\title{
EVOLUTIONARY SOCIAL COGNITION
}

\author{
Steven L. Neuberg and Mark Schaller
}

It is nearly trite to note that the human social world is complex, dynamic, and rich in information. It is also a well-worn trope in psychology that the human mind lacks the capacity to process all this information, online or otherwise. So what's a mind to do?

The answer is that the mind attends to some bits of information while ignoring others, uses a variety of mental shortcuts to reduce processing load, and generally engages a wide range of simplifying processes to muddle through in the face of an otherwise daunting task. Such social cognition is often viewed as irrational and error prone, with ill consequences for both perceivers and perceived.

The social mind is indeed a biased social information processor, but it is not arbitrarily biased. Rather, it is designed for a very specific purpose-a purpose that helps explain the ways in which, and why, social cognition is indeed focused and selective and biased. The mind is not designed to make perfectly correct decisions, and it is not designed to help people achieve happiness, a sense of control over their lives, on some greater meaning, although it may sometimes appear that way. Rather, the ultimate purpose of the mind is to enable people to manage the very real, very tangible opportunities and threats that humans have recurrently confronted across their evolutionary history in such a way as to enhance the individual's reproductive fitness.

The metatheory of evolutionary psychology assumes that the human brain, like all aspects of the human body, has been shaped by biological selection processes, with the general effect of increasing the success with which humans address recurring challenges to reproductive fitness (Buss, 1995; Ketelaar \& Ellis, 2000; Tooby \& Cosmides, 1992). As with other metatheoretical approaches-for example, social psychology or cognitive scienceevolutionary psychology is a set of assumptions that enable one to derive specific theories, models, and hypotheses that are themselves testable and subject to invalidation. Also, as with any metatheoretical approach, it can be evaluated against four important standards for scientific success: (a) its logical coherence; (b) its ability to enable the rigorous deduction of specific theories that explain the phenomena of psychology as we currently know them; (c) its ability to generate testable hypotheses that are interesting, novel, nuanced, and ultimately supported by data; and (d) its ability to connect phenomena at different levels of analysis and description. Judged against these criteria, the evolutionary approach to social psychology has proven to be quite successful (Neuberg, Kenrick, \& Schaller, 2010).

We focus here on evolutionary social cognitionhow everyday cognition is tied to the fundamental, recurring adaptive challenges of social life. We begin by articulating the logical foundations of evolutionary social cognition. We then discuss the ways in which evolutionary social cognition is inherently motivated social cognition and subsequently review a rapidly growing body of research demonstrating the presence of adaptation-based, functional social-cognitive processes aimed at managing challenges of self-protection, disease avoidance, resource acquisition, social affiliation,

http://dx.doi.org/10.1037/14341.001

APA Handbook of Personality and Social Psychology: Vol. 1. Attitudes and Social Cognition, M. Mikulincer and P. R. Shaver (Editors-in-Chief)

Copyright $\odot 2015$ by the American Psychological Association. All rights reserved. 
status acquisition, mate seeking, mate retention, and kin care. We close by briefly revisiting big lessons and highlighting promising arenas for future theorizing and exploration.

\section{LOGICAL FOUNDATIONS OF EVOLUTIONARY SOCIAL COGNITION}

An evolutionary perspective on social cognition assumes two elementary principles of genetic evolution and developmental biology. First, the genes that define contemporary human populations are the product of a long history of evolution by natural selection. This principle is noncontroversial. Second, the human nervous system typically develops according to a recipe encoded in those genes. This principle, too, is noncontroversial. When integrated, the following statement logically follows: The human nervous system is characterized by stimulus-response mechanisms of specific kinds that, compared with plausible alternative mechanisms, generally had positive implications for the reproductive fitness of the genes that make up the recipe for constructing the human nervous system.

This sentence is dense and requires some careful unpacking to be clear about what it says (and does not say). As we unpack it, we highlight 10 elements essential to the logic of an evolutionary approach to psychology, in general, and to social cogrition, specifically.

"The Human Nervous System ..." We purposely use the wordhuman to imply universality across all Homo sapiens. Underlying any evolutionary approach to social cognition is the assumption that the basic mechanisms of human psychology are universal across all normally developing indixiduals in all contemporary human populations An evolutionary approach to social cognition is thus dedicated to the elucidation of social-cognitive processes relevant to all people everywhere.

For this reason, just as cross-cultural evidence contributes to conclusions about the evolutionary bases of emotions (e.g., Ekman \& Friesen, 1971; Tracy \& Robins, 2008), cross-cultural research also plays an important role in evolutionary approaches to social cognition. Consider Cosmides' classic work (e.g., Cosmides, 1989; Cosmides \& Tooby, 2005) on cheater detection. Using the Wason selection task, which in its typical, abstract operationalization suggests striking flaws in people's reasoning ability, Cosmides and colleagues demonstrated that people instead perform quite well when the task is framed in the context of a social exchange relationship. Their conclusion-that this enhanced performance reflects an underlying set of cognitive adaptations that evolved as a means of detecting nonreciprocators in exchange relationships-is buttressed by a range of findings, including evidence that this pattern of reasoning is also evident in many cultural populations, including nonliterate Amazonian hunter-horticulturists (e.g., Harris, Núñez, \& Brett, 2001; Sugiyama, Tooby, \& Cosmides, 2002).

The assumption of universality does not, however, imply homogeneity in psychological responding, any more than an evolutionary approach to genetics implies that all people must be clones. Of course there are individual differences in human cognition and cultural differences, too. An evolutionary approach does implicitly assume, however, that although differences may be found at one level of psychological analysis, many of these differences may reflect universal psychological mechanisms operating at another, deeper level of analysis (Norenzayan, Schaller, \& Heine, 2006). One potential value of an evolutionary approach is that it compels researchers to try to identify those deeper (often nonobvious) underlying universal mechanisms.

\section{"Is Characterized by Stimulus-Response Mechanisms ...."}

Many social-cognitive phenomena function as stimulus-response mechanisms, in which specific sets of psychological inputs trigger specific kinds of psychological outputs (e.g., the visual perception of symmetrical facial features elicits the inference that the face is physically attractive; G. Miller $\&$ Todd, 1998). These stimulus-response relations often occur in cascades, in which a psychological response stimulates further responses, as when the inference that someone is physically attractive elicits additional emotional, cognitive, and behavioral responses. In many cases, the presence or magnitude 
of a particular stimulus-response relation is itself responsive to the presence of other stimuli. For example, the perception of symmetrical facial features may elicit rather different emotional, cognitive, and behavioral responses, depending on whether it is an opposite-sex or same-sex face or depending on the broader social context in which the face is perceived. A large part of this chapter focuses on how certain perceiver goals-themselves typically engaged by stimuli in the environmentact to modulate not only which stimuli in the social environment are perceived and attended to in the first place but also the responses these stimuli elicit. Evolved cognitive mechanisms tend not to operate in a fixed and closed manner but rather in a contextually contingent, situationally sensitive, and open manner (Mayr, 1976).

Whereas traditional research on social cognition is devoted to describing and explaining these kinds of stimulus-response relations in terms of mechanisms operating at an individual level of analysis, a rigorous evolutionary approach to social cognition requires that researchers also articulate the population-level evolutionary processes that explain how these stimulus-response mechanisms came to characterize humans in the first place. In other words, an evolutionary approach to social cognition is defined by attempts to integrate proximate explanations of human social cognition with ultimate explanations as well. A considerable body of research has now emerged identifying the adaptive implications that specific physical features (including facial symmetry) have in the context of mating relationships, which in turn have empurically testable implications for the cognitive, emotional, and behavioral responses triggered by those features and traits and for the contexts under which those responses are either muted or exaggerated (e.g., G. Miller \& Todd, 1998: Néuberg et al., 2010).

\section{"Of Specific Kinds That ...."}

Evolutionary analyses of social cognition frequently yield hypotheses highly specific in terms of content. This content specificity stands in contrast to many other approaches to social cognition that focus primarily on process (e.g., attribution processes through which individuals form impressions on the basis of observed behavior, social identitybased inference processes through which negative out-group stereotypes are formed, retrieval processes through which information is activated into working memory). Underlying much of this traditional process-oriented research is the tacit assumption that the content of these processes is irrelevant or, at least, interchangeable. For example, the same attribution processes are prestumed to underlie inferences about friendliness, nervousness, or attitudes about communism; the same social identity processes are seen to contribute to stereotypes about ignorance, untrustworthiness, or criminal behavior; and the same implicit memory processes are invoked regardless of what kind of information might be ayailable for retrieval into working memory

Evolutionary approaches have revealed that this tacit assumption overlooks deeper nuances pertaining to the psychological processes through which people cognitively respond to their social environment. Just as unique brain structures are used when processing specific kinds of visual stimuli associated with unique evolutionary implications (e.g., the human body, faces; Downing, Jiang, Shuman, \& Kanwisher, 2001; Kanwisher, McDermott, $\&$ Chun, 1997), unique reasoning mechanisms appear to be used when making decisions in specific kinds of social contexts that had unique evolutionary implications (e.g., social exchange contexts; Cosmides, 1989). The same principle applies broadly across a wide range of social-cognitive phenomena. People may more readily form impressions about some specific traits rather than others; people may more readily form stereotypes that discriminate along some specific negative attributes rather than others; and particular kinds of stereotypes, rather than others, may be especially likely to be activated into working memory. Predictions about these content-specific responses are readily deducible when one rigorously applies the logical tools of evolutionary psychology. The result is a body of research that not only contributes in novel ways to the understanding of social-cognitive processes but also reveals many novel conclusions about the highly specific content of inferences and attitudes that emerge from those processes. 
One illustrative line of research has explored inferential responses to babyish facial features. Adaptive behavioral responses to neonatal offspring (e.g., the provision of parental care) would have been facilitated by cognitive mechanisms implicitly linking certain perceptual stimuli (e.g., babyish features) to inferences about traits characteristic of individuals requiring care (e.g., "This individual is incapable of taking care of him- or herself and is worthy of my assistance"). One consequence of this stimulus-response mechanism is that perceivers draw these implicit inferences not only about babies but also about a predictable subset of adults, too: Baby-faced men are judged to be relatively nice but also relatively naïve and incompetent (Zebrowitz \& Montepare, 2006; see Chapter 7, this volume). Note that baby-facedness does not elicit a generally positive overall impression or a generally negative overall impression. Rather, it simultaneously elicits a very specific kind of positive impression (nice rather than nasty) and a very specific kind of negative impression (incapable rather than capable).

The same point is also illustrated by research documenting highly specific linkages between perceived threats and the contents of group prejudices. Members of different social groups are perceived to pose different kinds of threats to survival and reproduction. For instance, European American undergraduates in one study perceived Mexican Americans as posing a threat to physical safety, whereas they perceived gay men as posing a threat to health (Cottrell $\&$ Neuberg, 2005). An evolutionary approach to prejudice implies that these distinct forms of threat are likely to elicit qualitatively distinct kinds of prejudicial responses, and they do: Mexican Americans elicited more fear than did gay men, whereas gay men elicited more disgust than did Mexican Americans (Cottrell \& Neuberg, 2005). It is worth noting that the overall evaluative attitude toward both groups was equally negative and that these superficially similar attitudes masked fundamental differences in their specific affective and connotative contents.

Unlike many other approaches, then, the evolutionary approach often makes novel, nuanced predictions about the content of social cognition. To evolutionary social cognitivists, content, as well as process, matters.

\section{"Compared With Plausible Alternative Mechanisms ...."}

People sometimes assume that evolution creates optimal organisms, with the implication that any evolved mental mechanism should be just about perfect. This assumption is wrong. People sometimes also assume the corollary that evolutionary processes cannot legitimately be used to explain imperfect processes. This assumption is also wrong. Natural selection is not a forward-looking, creative process. Rather, it is a winnowing process, the outcomes of which are constrained by available genetic alternatives. If the available alternatives are genes that make people dumb and genes that make people dumber, then evolutionary processes may produce a population that is dumb rather than dumber. They cannot, however, produce a population any smarter than that.

Evolution is also constrained by basic principles of physics, chemistry, and biology. Consider, for example, psychological mechanisms used in the service of recognizing kin. To inhibit incest (which can impose costs on reproductive fitness) and to facilitate nepotism (which can benefit reproductive fitness), adaptive advantages would have been associated with mental mechanisms enabling perceivers to discriminate between other individuals according to their degree of genetic relatedness. An ideal mechanism for doing so would provide instant perceptual access to another individual's actual genetic makeup and would compute an unerring index of self-other genetic similarity. Any such magical mechanism is as physically implausible as $\mathrm{X}$-ray vision. Instead, the problem of kin recognition in humans and other animals appears to have been solved by the evolution of stimulus-response mechanisms sensitive to superficial cues (e.g., facial resemblance) that are correlated with kinship, albeit imperfectly (Lieberman, Tooby, \& Cosmides, 2007; Park, Schaller, \& Van Vugt, 2008). The imperfect diagnosticity of these cues results in predictable inference errors in which kin are sometimes treated as nonkin and nonkin are sometime treated as kin-an important point we elaborate on in the next section.

Evolutionary processes are additionally constrained by the cumulative physiological consequences of 
previous evolutionary adaptations-which may be impossible to undo even if they are no longer functionally useful. For example, relatively recent evolutionary adaptations in neocortical physiology endow humans with the capacity to use logical reasoning processes and abstract symbols (e.g., linguistic labels for kin members) to ascertain another person's degree of genetic relatedness with formidable accuracy. In an ideal world, perhaps, the evolutionary emergence of these neocortical capacities would be accompanied by the simultaneous disappearance of the older, cruder (and more error-prone) cue-based kin recognition mechanisms. However, that is rarely the way evolution works. Inferences about kinship continue to be implicitly informed by evolutionarily ancient cue-based stimulus-response mechanisms, which has broad implications. Even in interactions with total strangers, for instance, phenotypic resemblance triggers kin-connoting inferences. Oppositesex strangers with faces that merely resemble the perceiver's own are judged both as more trustworthy and as less sexually attractive-a pair of inferences that makes good sense for actual kin (DeBruine, 2005). Attitude similarity may also serve as a heuristic cue for kinship: Compared with strangers with dissimilar attitudes, attitudinally similar strangers are implicitly associated with semantic concepts connoting kinship (Park \& Schaller, 2005). The intriguing implication is that many social psychologícal consequences of incidental similarities-including similarities that ostensibly have nothing to do with familial relationships at all-may result, in part, from the implicit operation of ancient cue-based mechanisms of kin recognition. These phenomena include the well-documented effects of attitude similarity on interpersonal liking, the effects of nominal similarity on preferences and decision making (i.e., the nameletter effect), and the effects of various arbitrary similarities (such as sharing a birthdate) on achievement motivation and task performance (e.g., Byrne, 1961; J.T. Jones, Pelham, Carvallo, \& Mirenberg, 2004; Walton, Cohen, Cwir, \& Spencer, 2012; for a review, see Park et al., 2008).

"Generally ...."

The adaptive implications of psychological responses cannot be revealed by consequences idiosyncratic to one particular instance or one particular individual. A particular cognitive disposition may have had no beneficial implications at all under many circumstances (and may even have been costly under some circumstances) yet may still have proven evolutionarily adaptive when considering its relative reproductive benefits across all circumstances and across all individuals in a population.

This point attests further to the inevitable imperfection of evolved psychological processes and also suggests that the exact nature of those imperfections can be predicted by applying a cost-benefit logic that underlies rigorous evolutionarytheorizing. One useful logical tool is the smoke detector principle (Nesse, 2005), in which the adapted design of the human mind is likened, metaphorically, to the intentional design of smoke detectors that homeowners install on their ceilings. Smoke detectors are signal detection device's and have the potential to make false positive errors (erroneously signaling the presence of a house fire when there is no such fire) and false negative errors (erroneously failing to signal the presence of an actual fire). Any attempt to systematically minimize one kind of error increases the likelihood of the other. Both errors are equally erroneous, but they differ greatly in their costs: False-positive errors are merely irritating, whereas false-negative errors can be devastating. For this reason, smoke detectors are deliberately calibrated to minimize the possibility of a false-negative error, with the inevitable consequence that they make many false-positive errors. Analogously, many psychological stimulusresponse mechanisms also serve a signal detection function (e.g., the detection of anger, or kinship, or fertility) and so also have the potential to produce both false-positive and false-negative errors. These errors also typically differ in their costly implications for reproductive fitness and so, as a result of natural selection processes, these mechanisms show predictable adaptive biases: They err on the side of minimizing the likelihood of the most costly errors, with the inevitable consequence that they instead produce many errors of a less costly kind (Haselton \& Nettle, 2006). This principle, and the evolutionary costbenefit logic that underlies it, can be used to deduce novel predictions pertaining to the biases and errors that characterize social cognition. 
One illustrative application of the smoke detector principle can be found in a line of research linking interpersonal prejudice to the psychology of disease avoidance. Infectious diseases posed a threat to survival (and thus to reproductive fitness) throughout human evolutionary history. As a consequence, a behavioral immune system appears to have evolved (Schaller, 2011; Schaller \& Park, 2011). It is characterized by psychological mechanisms that respond adversely to perceptual cues connoting the presence of disease-causing pathogens in other individuals (e.g., anomalous morphological features). Because these superficial cues are only imperfectly correlated with actual infection, however, inference errors are inevitable. False-positive errors lead to the avoidance of healthy people (who are erroneously judged to be infectious); falsenegative errors lead to failures to avoid infectious people (who are erroneously judged to be healthy). False-positive errors typically have minimal consequences for perceivers, but false-negative errors can be fatal. In accordance with the smoke detector principle, the behavioral immune system is characterized by an adaptive inference bias that minimizes the likelihood of false-negative errors, with the consequence that it makes many false-positive errors instead. Thus, even when people have rational knowledge to the contrary, the perception of anomalous physical features in other people cantrigger aversive responses characterized by disgust and the automatic activation of disease-releyant semantic concepts into working memory. These mechanisms contribute uniquely to prejudices against people who are obese, elderly, orphýsically disabled (Duncan \& Schaller, 2009; Park Faulkner, \& Schaller, 2003; Park, Schaller, \& Crandall, 2007) and to ethnocentrism and xenophobia as well (Faulkner, Schaller, Park, \& Duncan, 2004; Navarrete \& Fessler, 2006).

The evolutionary logic of error management also has implications for sex differences in social inference biases within cross-sex interactions. Throughout evolutionary history, female mammals have been obligated by physiology to make a larger investment per offspring than males (differential parental investment). The maximum number of offspring that a female can produce is also smaller (constrained not only by gestation and lactation but also by menopause). Each individual offspring has thus been of greater reproductive value to females than to males, with the implication that female mammals tend to be pickier in their choice of male mates: The extent to which male mates are capable of producing genetically fit offspring, and are willing to invest resources in offspring care, has been greatly important. For female perceivers, then, the reproductive cost of erroneously inferring positive qualities in a potential mate (a false-positive error) was typically greater than the cost of failing to perceive positive qualities that actually exist (a falsenegative error). The adaptive implication of this cost asymmetry is a female bias toward skepticism about the positive qualities of potential mates (Haselton $\&$ Buss, 2000). In contrast, for male perceivers, the cost of failing to avail oneself of a willing mate (a false-negative error) was typically greater than the cost of erroneousty inferring a willingness that did not actually exist (a false-positive error). The adaptive implication is a male bias toward overperceiving females sexual desire (Haselton \& Buss, 2000).

Evolved social-cognitive mechanisms are thus not expected to generate perfect outcomes. Rather, the very nature of their design-to avoid errors that, generally, are highly reproductively costly-means that these mechanisms will inevitably generate a different set of predictable, but less reproductively costly, errors.

"Had ..."

The emphasis here is not on the verb itself but on the fact that it is expressed in the past tense: had (not has). This is important. It is an empirical question whether any particular psychological phenomenon has positive implications for future reproductive fitness within contemporary ecological circumstances. Moreover, although this question of current adaptiveness may interest some scholars who study human behavioral ecology, it is mostly irrelevant to scientific inquiry into social cognition. Although there is no reason to assume that any psychological phenomenon has implications for fitness within contemporary ecologies, very good reasons exist to assume that many psychological phenomena had implications for fitness within enduring ancestral ecologies. It is thus misleading to declare 
that the mind is adaptive and more appropriate to recognize that it is adapted-adapted specifically to the kinds of physical and social ecologies that characterized the bulk of human evolutionary history. Adaptations need not be currently adaptive.

For this reason, the point of departure for most research in evolutionary social cognition is the identification of a reproductive challenge in ancestral ecologies_-an enduring feature of local ecological circumstances that either provided an opportunity for enhanced reproductive fitness or imposed an obstacle to reproductive fitness. The next step is to identify some specific psychological mechanism or mechanisms that might plausibly have addressed that challenge in such a way as to exert positive effects on reproductive fitness and, as a consequence, to have eventually become widespread in ancestral populations. Ideally, these lines of deductive reasoning yield novel hypotheses about psychological phenomena in contemporary environments. These hypotheses can be tested against empirical data.

Because these hypotheses are logically rooted in speculations about the historical past, their a priori plausibility depends on the extent to which these speculations are themselves plausible or supported indirectly by scientific evidence of various kinds (Conway \& Schaller, 2002; Schmitt \& Pilcher, 2004). Evolutionary hypotheses specifying sex differences in mating cognition (e.g., Buss, Larsen, Westen, \& Semmelroth, 1992; Kenrick \& Keefe, 1992) are informed by physiological and cross-species evidence attesting to the fact that the male-female difference in obligatory parental investment is not a recent phenomenon but is an extremely ancient and enduring characteristic of all mammalian populations. Speculations about social structures of ancestral ecotogies (hierarchical relations within groups, the nature of intergroup interactions, etc.) are necessarily more speculative but can be informed by anthropological and primatological evidence. Evolutionary hypotheses about intergroup cognition are buttressed by extensive ethnographic observations of relations between contemporary human huntergatherer groups and by studies of contemporary nonhuman primate groups as well (Schaller $\&$ Neuberg, 2008, 2012).
By looking to the ancestral past as a means of deducing hypotheses about the psychological present, an evolutionary approach facilitates discovery of social-cognitive phenomena unlikely to emerge from other approaches to social cognition. Research on the behavioral immune system offers one example. Because most social cognition research is conducted within contemporary populations in which the risk of contracting debilitating infectious diseases is minimal-thanks to modern advances in medicine and public health systems-it is unsurprising that the subtle influence of disease-avoidant processes on prejudice and person perception remained almost entirely overlooked. Only by explicitly recognizing that humans' nervous systems are adapted to ancient ecologies (within which infectious diseases imposed tremendous selection pressures on ancestral populations) did thesenovel social-cognitive phenomena begin to be uncovered.

\section{"Positive Implications for the Reproductive Fitness ..."}

As with other functional approaches to psychology, evolutionary approaches to social cognition are based on a cost-benefit calculus. But it is a calculus of a very specific kind: Costs and benefits are not defined in terms of affective experiences or selfesteem or material resources or any other outcome that might be considered functionally beneficial in a merely psychological or economic sense. Rather, these costs and benefits are defined specifically in terms of reproductive fitness-the extent to which one's genes are transmitted to subsequent generations. This particular kind of functional approach is conceptually distinct from traditional psychological approaches that emphasize motives and goals but is entirely compatible with those approaches as well. Psychological phenomena that are functional in an evolutionary sense (because they had positive implications for reproductive fitness in ancestral environments) are typically associated with the psychological experience of emotions, need states, or goal constructs of the sort discussed in the psychological literature on motives and goals (Bargh, Gollwitzer, \& Oettingen, 2010; Kenrick, Griskevicius, Neuberg, \& Schaller, 2010). For this reason, most programs of research in evolutionary social cognition 
fit comfortably within the broader psychological literature linking affective experiences and goal states to social-cognitive phenomena. Reproductive fitness is an easily misunderstood concept. Given the prominence of the word reproductive, it is tempting to presume that -in the human contextit pertains specifically to the domain of mating and sexual behavior. This presumption is wrong. Although the psychology of sexual relationships does indeed have implications for reproductive fitness, the same is true for psychological processes operating in other domains of social life as well.

For instance, our ancestors were almost certainly less likely to produce offspring and successfully raise them to reproductive age if they were excluded from their social group. Consequently, cognitive responses that promoted the formation (and maintenance) of platonic relationships are likely to have had positive consequences for reproductive fitness. One implication is that when the risk of social exclusion is salient, people exhibit specific person perception biases—such as more positive first impressions of potential interaction partners-that promote the establishment of new social connections (Maner, DeWall, Baumeister, \& Schaller, 2007).

Also, our ancestors were less likely to produce offspring if they died at an early age; as a consequence, cognitive processes pertaining to the detection of threats (including social threats) of various kinds had implications for reproductive fitness. For this reason, evolutionary cost-benefit analyses have yielded many novel discoveries about attention to, memory for, and inferences about people who pose specific kinds of fitness-relevant threats-including, but not limited to, the threat of interpersonal violence, the threat of disease transmission, and the threat of nonreciprocation (Ackerman et al., 2009; Becker, Kentick, Neuberg, Blackwell, \& Smith, 2007; Buchner, Bell, Mehl, \& Musch, 2009; Huang, Sedlovskáya, Ackerman, \& Bargh, 2011).

And so on. It has become increasingly clear that an enormous range of processes pertaining to social perception, social inference, and social attitudes are likely to have had implications for reproductive fitness and so can be more deeply and completely understood when examined through the lens of evolutionary inquiry (Neuberg et al., 2010). Much of this chapter is devoted to the wide variety of goals fundamentally tied to reproductive fitness and their implications for social cognition.

\section{"Of the Genes ..."}

There is also another way in which the core concept of reproductive fitness is easily misunderstood: The underlying logic pertains not to the reproduction of individual organisms but instead to the reproduction of genes. From an evolutionary perspective, living organisms (including human beings) are vehicles for genetic replication (Dawkins, 1976). Humans' nervous systems are designed by genes to perform specific kinds of motor behaviors (and to perform them selectively in specific kinds of situations) to facilitate the successful reproduction of those genes.

Psychological phenomena that had implications for the outcomes of close kin therefore had indirect implications forindividuals' own reproductive fitness (Hamilton, 1964a, 1964b). This "gene's-eye" view of human psychology usefully, and uniquely, yields novel discoveries pertaining to the psychology of kinship—a topic of considerable importance that, until recently, was almost entirely overlooked in the social psychological literature. Some of this work pertains to overt acts of behavioral decision making (e.g., decisions to help individuals of varying genetic relatedness; e.g., Burnstein, Crandall, \& Kitayama, 1994). Other findings pertain to the allocation of other kinds of psychological resources (e.g., attentional and emotional investment in the romantic affairs of kin members; A. P. Buunk, Park, \& Dubbs, 2008; Faulkner \& Schaller, 2007). Also, given that kinship has had important implications for the reproductive fitness of genes, the cognitive mechanisms of kin recognition-discussed earlier-have had important implications too.

A gene's-eye view also underlies a burgeoning body of research on female mate preferences and the manner in which specific preferences vary across a woman's menstrual cycle. The reproductive fitness of a gene depends not merely on its replication in the next generation but also on its replication in each generation that follows. From a gene's perspective, it is important not only that people produce offspring but that they produce healthy offspring who are likely to grow up to be reproductive adults 
themselves. And (following from the consequences of differential parental investment) this is especially the case for genes residing in female bodies. The adaptive implication is that when selecting potential mates, women are likely to selectively prefer mates who are most likely to endow their offspring with "good" genes-genes that

have an effect on embryonic development of each successive body in which they find themselves, such that that body is a little bit more likely to live and reproduce than it would have been under the influence of the rival gene or allele.

(Dawkins, 1976, p. 36)

Furthermore, given that the reproductive benefits of this selective preference for good genes accrue only when woman are likely to conceive a child, this preference is especially likely to be observed during the fertile phase of a woman's menstrual cycle. Consistent with this analysis, women do selectively discriminate between potential mates on the basis of good genes-signaled by phenotypic traits such as bilateral bodily symmetry, muscularity, facial masculinity, and body odor and by behavioral evidence of creativity and intelligence (G. Miller \& Tod\& 1998) — and they do so especially during the wo fertile phase of their menstrual cycles (Gangestad, Thornhill, \& Garver-Apgar, 2005; Haselton \& Miller, 2006; Penton-Voak \& Perrett, 2000).

\section{"That Make Up the Recipe for Constructing .}

An individual's genetic makeup can be usefully likened to a complicated recipe in a recipe book. This recipe provides instructions for assembling the phenotypic features of an organism. As with the outcome of any set of instructions, however, the eventual outcome depends fundamentally on that aśsembly process-development—and the specific circumstances in which it takes place. This phenotypic plasticity was itself adaptive because, throughout human evolutionary history, the implication of a particular phenotypic trait on reproductive fitness was likely to have varied depending on local circumstances.
This principle of phenotypic plasticity has important implications for the development of the stimulus-response mechanisms that characterize adaptive human psychology. One general implication is that evolved cognitive mechanisms are likely to develop differently under different neurochemical environments-as evidenced by the fact that hormone levels during development are linked to individual differences in adult cognition and behavior (Cohen-Bendahan, van de Beek, \& Berenbaum, 2005). This adaptive epigenetic process almost certainly accounts for many evolved sex differences in social cognition.

Another important implication is that evolved social-cognitive mechanisms are likely to manifest differently under different ecological circumstances, which provides a means of predicting additional individual differences in social cognition and behavior and of predicting cultural differences as well. One illustrative program of research has focused on regional variability in the prevalence of infectious diseases and its role in the emergence of cross-cultural differences of various kinds, including cultural differences in mate preferences, dispositional tendencies toward extraversion and openness to experience, attitudes regarding obedience and conformity, and individualistic versus collectivistic social values (Fincher, Thornhill, Murray, \& Schaller, 2008; Gangestad, Haselton, \& Buss, 2006; Murray, Trudeau, \& Schaller, 2011; Schaller \& Murray, 2008; for a review, see Schaller \& Murray, 2011). This body of research highlights the fact that evolutionary perspectives on human cognition are compatible with cross-cultural differences (just as they are with individual differences more generally) and that, in fact, evolutionary analyses provide useful means of predicting the origins of cross-cultural differences in the first place.

Just as evolved social-cognitive mechanisms are sensitive to features of the immediate situation, then, they are also sensitive to developmental and broader cultural circumstances. Context matters.

\section{"The Human Nervous System"}

We return again to the phrase we began with (see "The Human Nervous System ... ." section), but here we draw attention to a different piece of the phrase: 
nervous system. This choice of words is deliberate, for two reasons.

First, when we talk about the nervous system, we are talking about anatomy and physiology. Although most research on social cognition proceeds without explicit attention to human anatomy and physiology, an evolutionary approach to social cognition reminds researchers that psychological phenomena must, eventually, be connected to the biological entities that make up the organisms that genes build as a means of reproducing themselves. Thus, whereas traditional approaches to social cognition provide a principled agenda for integrating the social with the cognitive sciences, an evolutionary approach provides a principled agenda for further integrating the social and cognitive sciences with the biological sciences as well.

Second, when we talk about the nervous system, we are talking about more than just the brain. The nervous system extends throughout the entire body. This is important because humans' nervous systems (including their brains) are not designed merely to make sense of perceptions and to draw inferences and to arrive at judgments about the world around them, they are also designed to translate these cognitive responses into adaptive action-muscle movements that, historically, had beneficial implications for reproductive fitness. From an evolutionary perspective, social cognition operates in serrice to actual behavior.

For this reason, evolutionary inquiries into human social cognition can beabetted not only by the tools of cognitive neuroscience (which focus on that part of the nervous system that resides inside the skull) but perhaps even more so by the tools of behavioral neuroscience, which focus on a broader set of physiological systems that manifest throughout the entire body and are implicated in the production of fitness-relevant behavior. One illustrative line of research focuses on testosterone as an important link in the causal chain of events connecting social-cognitive processes to adaptive behavior. For example, the mere perception (through olfactory cues) of ovulating women leads to increased production of testosterone within the bodies of male perceivers (S. L. Miller \& Maner, 2010b). This neurochemical response facilitates the sorts of behaviors (e.g., competitive actions and other status-enhancing displays; e.g., Archer, 2006; Mazur \& Booth, 1998) that, historically, positioned males to have greater access to mates. In contrast, men show reduced production of testosterone after those life events-such as the birth of offspring - that represent an adaptive shift in motivational priorities away from mate acquisition and toward parental care instead (Gray, Kahlenberg, Barrett, Lipson, \& Ellison, 2002).

In sum, the mind is embedded in the body and people think about others so that they might act toward them in ways that would have improved the odds, in humans' ancestral history, of facilitating their reproductive fitness.

\section{Stereotypic Misconceptions Briefly Noted and Corrected}

The preceding elements underlie the logic of an evolutionary approach to social cognition. Before moving on, it is useful to address directly several ways in which these elements contradict common misconceptions of the evolutionary approach.

First, the evolutionary approach neither assumes, nor requires, human cognition and behavior to be biologically determined or inflexible. To the contrary, evolved mechanisms are phenotypically plastic in development and functionally flexible in application. Although genes provide a recipe for assembling an individual, the developmental context-for example, the neurochemical environment in utero and early learning experiencesshapes the expression of evolved mechanisms in the resulting person. Moreover, different local and cultural contexts engage some evolved mechanisms in the individual's repertoire more than do others. Processes of development, learning, and culture are inherent to an evolutionary approach to psychology. From an evolutionary approach, context-developmental, learning, social, and cultural-matters.

Second, it is sometimes assumed that the presence of cultural differences in a psychological phenomenon is evidence against an evolutionary explanation for it. The evolutionary approach does assume that the basic mechanisms of human psychology will be universal across normally developing individuals. However, the approach does not assume that these universals will reveal themselves, across 
cultures, as similarities at the level of readily observed behavior. Cultures can provide different developmental, learning, and social contexts for their members, and these differences can shape how psychological universals play out. Indeed, differences at a surface level of analysis can, and often do, reflect universal mechanisms operating at a deeper level of analysis (Norenzayan et al., 2006). Moreover, many of the processes by which cultural differences emerge-for example, social learningare themselves evolved psychological mechanisms (Henrich \& Boyd, 1998; Moore, 2004) evident not only in human infants (e.g., Mumme \& Fernald, 2003) but also in nonhuman primates (e.g., Cook \& Mineka, 1990).

Third, people sometimes assume that for a psychological mechanism to be an evolved adaptation it must operate optimally, without error. The supposed corollary of this is that any mechanism that operates imperfectly must thus not be an adaptation. Neither of these is correct. As we discussed, natural selection is not a forward-looking process seeking to create perfect social-cognitive mechanisms but rather a winnowing process eliminating less-good mechanisms. Moreover, although evolved adaptations were historically relatively beneficial (conpared with alternatives) across individuals in population, this does not mean that theyever led, or would be expected to lead, to mistake-free behavior at the level of the individual. Furthermore, because adapted mechanisms were designed to eliminate the most costly of mistakes, they will inevitably generate other (albeit less historicalty costly) mistakes. Last, such mechanisms were selected to address problems and circumstances of the ancestral past; to the extent that the present is fundamentally different, those adaptations would not be expected to be currently adaptive.

\section{THE SELFISH GENE MEETS THE SELFISH GOAL: EVOLUTION, MOTIVATION, AND SOCIAL COGNITION}

Richard Dawkins's (1976) book The Selfish Gene is deservedly famous for its forceful presentation of the gene's-eye view of behavior. More important, it is a view that explicitly highlights the adaptive role of psychological mechanisms-learning, memory, and other elements of cognition. Dawkins reminds readers that, although genes design and build bodies with the capacity to behave in fitness-enhancing ways, genes cannot exert immediate control over those bodies' behaviors in any given instant. Genes are many causal steps removed from any specific act of cognition or behavior. It is for this reason that there evolved sophisticated nervous systems. "Genes are the primary policy makers," wrote Dawkins (1976, p. 19), but "brains are the executives."

Bargh and Huang (2009) paid explicit homage to this point in a chapter cheekily titled "The Selfish Goal." They observe that if brains are the executors of the genes' reproductive objectives, then "goal pursuits .. are the executive processes of the brain" (Bargh) \& Huang, 2009, p. 131). Moreover, when a goal is activated, it can be considered just as metaphorically selfish as a gene: "Active goals single-mindedly pursue their agenda independently of whether doing so is in the overall good of the individual person" (Bargh \& Huang, 2009 , p. 131). And, just as people have no conscious awareness of the enormous impact that genes have on their behavior, they are often entirely unaware of the implicit impact that motives and goals have on attention, perception, cognition, judgment, and behavior.

An evolutionary perspective on social cognition implies even deeper-and not merely analogicalconnections between genetic reproduction and the impact of goals on human psychology. There are countless goal states that humans might experience, many of which are specific to particular people, particular objects, or particular contemporary contexts (the desire for a new car, the objective to adhere to a gluten-free diet, etc.). There is no reason to suppose that every goal state had implications for genetic reproduction, but there is every reason to suppose that some goal states did and that they reflect the operation of a smaller set of adaptive motivational systems that evolved because-by influencing perception, cognition, judgment, and behavior in specific ways-they facilitated the reproduction of the genes that built those motivational systems. 


\section{A New Pyramid of Fundamental Human Motives}

Just which motivational systems might plausibly be evolutionarily fundamental and have important consequences for social cognition? Kenrick, Griskevicius, et al. (2010) attempted to address this question by revisiting Maslow's (1943) famous pyramid of human needs and renovating it to reflect a more contemporary approach to human motivation informed not only by principles of cognitive activation and development but also by the logic of evolutionary biology. This logic demands that any truly fundamental motive must have had clear implications for reproductive fitness in ancestral ecologies and must have universal relevance to human beings (Schaller, Neuberg, Griskevicius, \& Kenrick, 2010).

Enhancing reproductive fitness implies much more than merely finding sex partners and copulating. Reproductive fitness also requires that individuals survive to reproductive age, which, for our ancestors, meant avoiding predation, avoiding disease, and acquiring nutrition and other resources. Moreover, humans have long been highly ultrasocial animals, with their outcomes highly dependent on the actions of others (Brewer, 2001; D. T. Campbell, 1982; Richerson \& Boyd, 1995). Our ancestors thus needed to address the challenges inherent to social affiliation and status seeking successfully. Moreover, human young mature quite slowly to accommodate the learning of complex and often subtle information and behaviors needed to manage interdependent ultrasociality (e.g., Dunbar, 2003). Survival throughout this lengthy period of immaturity would have been impossible in the absence of parental investment in child rearing, thereby selecting for a parental inclination in both mothers and fathersto enhance theirinclusive fitness via care for their young. The fittress benefits of dual-parent investment would have pulled for long-term parental pair bonding, making the challenge of mate retention an important one. These goal domains-self-protection, disease avoidance, resource acquisition, social affiliation, status acquisition, mate seeking, mate retention, and child rearing - are thus fundamental in the sense that they have long been arenas of challenge to reproductive fitness faced by humans (Kenrick, Griskevicius, et al., 2010).
It is useful to note that, whereas research and theorizing in social cognition has traditionally focused on goals related to epistemics (e.g., accuracy, belief confirmation) or self-regard (e.g., enhancement, verification, affirmation), an evolutionary approach brings into relief a very different set of goals-those fundamental to solving the long-recurring and tangible physical and social challenges faced by humans. Four of these goals, in particular-disease avoidance, resource acquisition, mate retention, and child rearing — have traditionally received fittle research attention, yet one would be hard pressed to suggest that they are not focal to manyeveryday lives. Indeed, they may even dominate people's motivational hierarchies during certain life stages. Recognition of these oversights is one of many novel contributions of the exolutionary approach.

\section{Motive Activation and Adapted Social Cognition}

These fundamental motivational systems may vary (acrossindividuals, across ecological contexts) in the extent to which they are chronically activated. Evolutionary cost-benefit calculations can be highly useful for predicting the exact nature of these differences in chronic activation-and thus for predicting differences in their downstream effects on cognition and behavior. For example, the evolutionary logic of differential parental investment implies differences between men and women in chronic activation of motives pertaining to mate acquisition, which, in turn, implies predictable sex differences in person perception and person memory (we discuss many examples). Predictable developmental differences in chronic activation of these motivational states also exist. The motivational system pertaining to mate acquisition is likely to be more chronically activated among people in their teens and 20s than among people in later stages of life, and the motivational system pertaining to parental care is likely to be more chronically activated among people who are actually parents of young children. These differences in chronic goal activation are signaled by predictable differences in neurochemistry (e.g., hormonal changes associated with the onset of parenthood; Hahn-Holbrook, Holbrook, \& Haselton, 2011) and have implications for a wide range of life stage-related 
differences in attitudes and social cognition. Clear individual differences in chronic activation exist as a result of the same general factors (e.g., genetic predispositions, socialization experiences) that lead to individual differences of any kind. As you will see, measures assessing individual differences in chronic motivations usefully predict important outcomes in the realm of attitudes and social cognition.

In addition to variation in chronic activation, these evolutionarily fundamental motivational systems are more likely to be temporarily activated in some situations than in others, simply as a result of perceptual exposure to contextual information implying goal-relevant threats and opportunities. Cues suggesting vulnerability to predatory danger temporarily activate a self-protective motive. Cues suggesting vulnerability to the transmission of infectious pathogens temporarily activate a diseaseavoidance motive. Cues suggesting the presence of an available sex partner temporarily activate a mating motive. Cues suggesting the presence of a desirable same-sex competitor temporarily activate a mate-retention motive, and so on. When any evolutionarily fundamental motivational system is temporarily activated (even by the kinds of obviously artificial means typically used in laboratory experiments), it is expected to have cognitive consequences of the sort that, in ancestral ecologies, facilitated adaptive behavioral outcomes'(Kenrick, Neuberg, Griskevicius, Becker, \&schaller, 2010).

\section{Functional Modularity and Domain- Specific Information Processing}

This evolutionary approach to motivation implies a shift away from the idea that the mind is a domaingeneral information processor. Humans descended from those who generated relatively better solutions for accomplishing these fundamental goals (Bugental, 2000; Kenrick, Li, \& Butner, 2003).

Bécause these goals are qualitatively distinct and require distinct solutions-the solutions to the challenge of finding a suitable mate, for instance, are quite different than the solutions to the challenge of retaining these mates - the brain would have evolved to be functionally modular and domain specific in the informational inputs it seeks and accepts, in its biases, and in the decisional and behavioral outcomes it generates (e.g., Barrett \& Kurzban, 2006).

The evolutionary approach thus anticipates that information processing is directed preferentially toward those specific people in one's social environment - and to specific features of those people - that are most logically relevant, in an ancestral sense, to one's currently active fundamental goals. Social cognition is a tool for managing the fitness-relevant opportunities and threats afforded by other people (Gibson, 1979; McArthur \& Baron, 1983; G. Miller, 2007; Neuberg, Becker, \& Kenrick, 2013). Social cognition is thus inherently, and always, motivated social cognition. Consistent with this, the research we review in this chapter demonstrates that the fundamental motive most salient at any moment shapes what people perceive in their social environments, where they focus their attention, how they interpret ambiguous information, which information they remember, how they manage possible errors in decision making, and the like.

\section{Self-Protection}

To enhance one's reproductive fitness, one must survive long enough either to produce offspring who themselves survive to reproduce successfully or to facilitate the survival and reproduction of genetically close relatives. In line with the evolutionary view that cognitive processes will generally be biased toward enhancing reproductive fitness, information related to survival is likely to receive certain processing advantages. For example, people better remember lists of items when the items are viewed as relevant to survival (e.g., Kostic, McFarlan, \& Cleary, 2012; Nairne \& Pandeirada, 2008, 2010).

Survival encompasses several motives, including self-protection, disease avoidance, and resource acquisition, and one would expect these different motivational systems to be sensitive to different cues in the environment, use different information to generate responses and decisions, and so forth. We begin with the self-protection system.

Historically, many threats to physical safety came from acts of nature and nonhuman predators. One would thus expect natural selection to favor genes that inclined our ancestors to bias their 
cognition toward effectively processing such threats Consistent with this, people are more accurate and faster at detecting changes in animals (that posed threats in ancestral ecologies) than at detecting changes in cars and trucks (that pose threats only in modern environments), even though, for the participant population, the vehicles pose a much greater daily threat to safety (New, Cosmides, \& Tooby, 2007). Similarly, contemporary humans more readily learn to associate shock-induced anxiety with ancestrally relevant threats (e.g., snakes) than with contemporary, but evolutionarily irrelevant, threats (e.g., broken electrical outlets). Moreover, this "prepared learning" of fear of ancestral threats is more resistant to extinction-that is, it is especially hard to unlearn-even though the modern threats afford greater risks of death in today's world (e.g., Öhman \& Mineka, 2001).

Many threats to physical safety arise from intentional acts of aggression from other humans. Assaults and murders, although not common to everyday social interaction, nonetheless occur with substantial frequency throughout the modern world. Homicide rates within hunter-gatherer groups-many of which occupy ecologies similar to the ones in which our ancestors evolved-are high as well (Chagnon, 1988), and intergroup conflict appears to have long characterized ancestral humans, as well as chimpanzees and other primate species (Haas, 1990; Pinker, 2011; Schaller \& Neuberg, 2008; Wrangham, 1987). It is clear that aggression at the hands of other humans has been a long-recurring challenge faced by humans. To address this challenge, it is likely that humans evolved a precautionary selfprotection system that is (a) attuned to cues suggesting the possibility of intentional physical harm from others and (b) equipped with affective, cognitive, and behayioral inclinations designed to reduce such threats when perceived (Neuberg, Kenrick, \& Schaller, 2011).

Anger often precedes intentional physical aggression and is often cued by readily and universally identified facial expressions (e.g., Ekman \& Friesen, 1975; Zebrowitz, Kikuchi, \& Fellous, 2010). Facial expressions are thus a heuristically useful, if imperfect, cue of impending threat to physical safety, and perceivers are indeed quite quick to detect and identify angry faces in their local environment (Becker et al., 2007).

Adult men and women have long differed in both their capacities and their inclinations to do significant physical harm, with men, on average, posing a greater threat of violence (A. Campbell, 2005; Daly \& Wilson, 1988). Given this sex difference in behavioral inclination, the great costs of being victimized by violence, and the cue value of angry facial expressions, one might hypothesize an inctination for humans to readily detect anger especially in the faces of adult men. In fact, research has revealed that perceivers more quickly and accurately identify male (vs. female) faces as angry and that angry expressions facilitate the identification of faces as male (vs. female; Becker et al., 2007). These results are not readily explained by a more general inclination toward enhanced or effective processing of adult men (vs.women), because adult women, who have historically differed from men in their greater capacity and inclination to provide succorance, are processed in a complementary way: Perceivers more quickly and accurately identify adult female faces as happy (an expression consistent with succorance), and happy expressions facilitate the identification of faces as female. These results are also not readily explained by learned sex stereotypes: When androgynous faces are dressed in sex-typed male versus female clothing, they are perceived as stereotypically masculine or feminine but not as correspondingly angry or happy (Becker et al., 2007).

Corroborating such findings, work on illusory conjunctions has demonstrated that, at the very early stages of visual perception, angry expressions on one face are especially likely to "leap onto" adjacent, emotionally unexpressive adult male (versus female) faces (Neel, Becker, Neuberg, \& Kenrick, 2012). Such findings have revealed that perceiving cues that heuristically imply physical safety threatsuch as angry facial expressions-leads to very rapid perceptual shifts biased toward creating the kinds of better-safe-than-sorry outcomes predicted by the smoke detector principle: If a target is male, err toward perceiving any nearby anger as belonging to him; if a facial expression is angry, err toward perceiving its expresser as male. 
Another feature likely to cue an individual's concern with physical safety is out-group membership: Consistent with both theorizing and empirical findings in humans and closely related primates, members of coalitional groups-in particular, young out-group men-have long been inclined toward intergroup aggression (Daly \& Wilson, 1988; Keegan, 1993; Keeley, 1996; Kelly, 2005; Navarrete, McDonald, Molina, \& Sidanius, 2010; Schaller \& Neuberg, 2008; Sidanius \& Pratto, 1999; Sidanius \& Veniegas, 2000; Van Vugt, De Cremer, \& Janssen, 2007; Wrangham \& Peterson, 1996). This inclination suggests that the processing of out-group men ought to be particularly prone to the self-protective biases. Much evidence for this exists, especially when the cue to out-groupness is race. It is useful to note, however, that such race biases tend to be greatly reduced when perceivers can readily identify other, more useful markers for out-group coalitional status (Kurzban, Tooby, \& Cosmides, 2001) or have reason to see themselves as sharing a meaningful coalitional membership with other-race individuals (Van Bavel \& Cunningham, 2009). Findings such as these further suggest that coalitional out-groupness, rather than race or ethnicity per se, serves as the critical psychological construct underlying self protective processing.

We mentioned earlier the concept of prepared associative learning - the evolved inclination to acquire and maintain associations that were ancestrally relevant to reproductive fitness more readily than associations that were Tess ancestrally relevant to reproductive fitness for instance, people are biologically prepared toracquire readily a fear response to snakes, which represented a significant threat in ancestral primate écologies (Öhman \& Mineka, 2001). People are also particularly efficient at learning, and particułarly inefficient at unlearning, fearful responsés to coalitional out-groups (Olsson, Ebert, Banaji, \& Phelps, 2005). Consistent with reasoning about the special threats posed by out-group men, this effect is specific to out-group male, but not female, targets (Navarrete et al., 2009).

In addition to biases in associative learning, people are also particularly cognitively attuned to out-group men, especially if other cues suggest hostility, which has intriguing implications for predicting the occurrence-and nonoccurrence-of the out-group homogeneity bias in recognition memory (in which people more accurately distinguish between faces of in-group members than faces of out-group members; e.g., Anthony, Copper, \& Mullen, 1992; Chance \& Goldstein, 1996). From an evolutionary perspective, limited processing resources should be allocated selectively to process information about individuats who afford significant fitness implications for oneself. Historically, those individuals would have been members of one's own coalitional in-group, with whom one regularly shares resources and pools efforts, mates, and so forth. One might thus expect a default processing advantage for in-group members, which would manifesst in greater recognition accuracy for in-group faces than for out-group faces. Individuals expressing anger should also attract considerable precessing resources. In fact, given that out-group members have historically posed a greater threat of hostile attack than in-group members (because interdependency within groups tends to inhibit the progression from anger to actual violence) and because angry facial expressions are fleeting (whereas hostile intent may endure), the faces of angry out-group men may be especially likely to attract perceptual processing of individuating features-and thus be especially likely to be recognized later. This line of reasoning implies that the out-group homogeneity bias in recognition memory might be eliminated, and even reversed, in the context of angry faces. Indeed, across a series of studies, White participants exhibited the typical out-group homogeneity recognition bias when encountering neutrally expressive faces-better recognizing previously seen White faces than Black faces-but showed no such homogeneity bias, and sometimes even a reversed out-group heterogeneity bias, when the faces bore angry expressions (Ackerman et al., 2006).

We have shown that self-protection concerns can be activated by certain features of individuals-for example, angry expressions, maleness, out-groupness-that serve to direct subsequent, additional goal-oriented processing toward them. Perceivers may also encounter potential physical safety threats with a self-protection concern already active-either because it is chronically active, as a disposition, or because it has been acutely 
activated by a recent event or the immediate context. Indeed, because selectively engaging and directing cognitive processing is costly-metabolically, as well in terms of opportunity costs (if one directs cognitive processing to achieve one goal, one is not using those resources to achieve other desirable goals) — the kinds of biases we have discussed should be especially likely to emerge when one's history of experiences or current circumstances suggest a special vulnerability. For instance, with respect to nonhuman threats, snakes are more readily detected by people who are dispositionally anxious (Öhman, Flykt, \& Esteves, 2001), and sudden noises produce more exaggerated fear responses among people who are in the dark and thus feel temporarily vulnerable (Grillon, Pellowski, Merikangas, \& Davis, 1997).

We discussed earlier that, at early stages of visual processing, angry facial expressions are disproportionately likely to be mistakenly perceived as belonging to male faces (Neel et al, 2012). Similarly, angry facial expressions in a crowd are especially likely to be misperceived by Whites as belonging on the faces of young Black men (relative to young White men). Of note here, this illusory conjunction is especially likely to occur for perceivers who dispositionally believe the world to be dangerous - that is, for those chronically concerned with self-protection (Becker, Neel, \& Anderson, 2010).

Consider also the process in which perceivers categorize ambiguous individuals as belonging to either an in-group or an out-group. Qut-group members-especially out-group men — have historically posed special dangers tophysical safety. Following the smoke detector principle of "better safe than sorry," it would have been adaptive to err on the side of categorizing a stranger as an out-group member than as an in-group member-and to do so especially under circumstances that heuristically connote threat. S. L. Miller, Maner, and Becker (2010; see also Maner, Miller, Moss, Leo, \& Plant, 2012) found that non-Black participants were especially likely to categorize targets as Black when the targets displayed heuristic cues to threat (masculine voices and body movements, movement toward the perceiver, angry facial expressions). They also found that independently activated self-protection concerns had similar effects: White participants were especially likely to categorize racially ambiguous angry male faces as Black when dispositionally concerned with danger and experimentally placed in a fear-inducing context (watching a clip from the film The Silence of the Lambs in a dark room vs. a control clip in a well-lit room). Vulnerability to threat leads perceivers to view heuristically threatening others as out-group members.

Self-protection concern elicits other biases as well. In another set of studies, White perceivers for whom self-protection goals were experimentally engaged (via film clip) "saw" anger in the neutrally expressive faces of Black men (Maneret al., 2005). The specificity of this error is intriguing and supportive of the evolutionary logic discussed here: The self-protection manipulatî̀ ndid not merely engage a broad negativity bias in perception because it did not lead perceivers to see other negative emotions on the Black mate fáces; it did not merely engage a general bias to see anger in men because it did not lead the White perceivers to see anger in the faces of Whitemen; and it did not merely engage a bias to see anger in out-group members because it did not lead perceivers to see anger in the faces of Black women. Rather, this bias was calibrated to prepare perceivers to address specifically the greatest presumed threat to physical safety-out-group men. According to the logic of the smoke detector principle, it is better to err by viewing a benign individual as potentially threatening than to view a potentially dangerous individual (as heuristically implied by out-group male status) as safe. The same psychology likely underlies biases exhibited in the shootdon't shoot experimental paradigm, in which White perceivers confronted with targets posed with a weapon (or not) exhibit biases toward shooting Black men and toward not shooting Black women and Whites of either sex (Plant, Goplen, \& Kunstman, 2011).

Other research has further demonstrated the nuanced processing in which protection-minded perceivers engage. As we have discussed, those who are believed to be aggressive-by virtue of imperfectly diagnostic features such as maleness, angry expressions, and out-group membership - tend to receive processing biased toward erring on the side of making the perceiver aware of potential danger. 
Given the tangible costs imposed by physically aggressive individuals, it should be no surprise that a set of such processing biases exists (in prepared learning, detection of emotional expressions, categorization, recognition memory, etc.) and appears to work in a redundant and precautionary manner to prepare perceivers for the dangers such men are believed to pose (Neuberg et al., 2011). Exceptions to this functional redundancy should exist, however, sensitive both to the functional needs of the perceiver and to the costs of redundancy. For instance, although visually attending to out-group men can potentially provide useful information about their intentions, such visual attention may be viewed by the target as intrusive or challenging, perhaps inviting the aggression that one fears. How should one manage such a dilemma? White participants in two studies who were experimentally primed to be concerned with self-protection (or not) became increasingly efficient at encoding Black and Arab male targets: Without increasing their visual attention to their faces, they nonetheless identified them quite well (compared with similar foils) in a subsequent surprise recognition test. As with other findings discussed earlier, this encoding efficiency was functionally focused: It emerged only in the processing of out-group male targets, not with White male or Black or Arab female targets - that is, only for targets stereotyped as dangerous (Becker, Anderson, et al., 2010).

Research has shown that threat-relevant stereotypes of out-group members are especially likely to bias processing of these individuals when perceivers are in a self-protective state of mind. Other research has shown that possessing such concerns in fact activates such stereotypes in the first place. In line with evidence that intergroup contact was likely to be associated with an increased chance of interpersona@aggression and physical injury (Schaller \& Neuberg, 2008) and following from the smoke détector principle, one might expect adaptations to evolve that would incline individuals to generate or bring to mind beliefs about out-group members as violent and dangerous, especially when circumstances imply that one is vulnerable to danger. Indeed, across a series of experiments, participants who felt particularly vulnerable to threat-because they dispositionally perceived the world to be a dangerous place and were temporarily in the darkexhibited greater activation of danger-connoting stereotypes of ethnic out-groups (Schaller, Park, \& Faulkner, 2003; Schaller, Park, \& Mueller, 2003). As with the functional specificity explicit in other studies, the activation of these stereotypes under physical safety threat was specific to stereotypes y related to safety threat but not to equally negative but threat-irrelevant stereotypes. In fact, some studies (e.g., Schaller \& Abeysinghe, 2006) have revealed that feelings of vulnerability may lead simultaneously to greater activation of a specific kind of negative stereotype (connoting hostility and aggression) and to greater activation of a specific kind of positive stereotype (connoting intelligence and overall competence). This pattern of results is inexplicable in many traditional social psychological theories of stereotypes and prejudice but makes perfect sense within the functional perspective outlined here because, compared with an incompetent aggressor, a competent aggressor poses a greater threat to physical safety. When the self-protection motivational system is activated, it does not simply activate negative beliefs about out-group members; rather, it activates a particular constellation of stereotypical beliefs that are most likely to facilitate a functional response to the implied fitness threat.

In sum, being concerned for one's safety leads people to process social information in functionally focused, nuanced ways. As we show, activating other motives fundamental to reproductive fitness leads to processing biases that are similarly focused and similarly nuanced.

\section{Disease Avoidance}

Reproductive fitness is threatened by others' potential for violence. It is also threatened by others' ability to spread disease. The physical proximity created by highly interdependent sociality potentially puts one in contact with disease-causing pathogens others may harbor on or within their bodies-a threat that imposed powerful selection pressures on ancestral populations (e.g., Ewald, 1994; Wolfe, Dunavan, $\&$ Diamond, 2007). One solution to the threat of pathogen exposure has been the evolution of a highly sophisticated immune system, designed to 
fight off pathogens once they have infected the body. A second solution has been the evolution of a behavioral immune system, designed to proactively avoid infection in the first place by detecting disease-causing pathogens in the immediate environment (including those in people) and then facilitating avoidance of those pathogens (Schaller, 2011; Schaller \& Duncan, 2007; Schaller \& Park, 2011).

Because most pathogens are not visible to the human eye, it has historically been nearly impossible to determine directly whether another person poses an infectious disease threat. Rather, people must use perceptible cues to infection to infer pathogen presence. Even this is difficult, however. Many species of pathogens exist, and they produce many different perceptible symptoms. Moreover, because pathogens evolve rapidly, these specific symptoms are ever changing, and different people may exhibit different symptoms even when infected with the identical pathogen. It would thus be impossible for a psychological system to acquire a full catalog of the specific observable symptoms that accompany infectious diseases. However, such a system can take advantage of the fact that, as a more general characteristic of infection, pathogens often reveal themselves by altering the body's morphology and motor behavior-for example, by creating poxes, rashes, and coughing spasms. Humans thus appear to have evolved a psychological precautionary system designed to detect not a list of specificdeviations from typical morphology and movement but rather the presence of any deviation from typical morphology and movement. It then uses anomalous appearance to implicitly connote the presence of infectious disease (Kurzban \& Leary, 2001; Oaten, Stevenson, $\&$ Case, 2011) and engage a set of functionally relevant affective and cognitive responses to facilitate behavioral avoidance of the individual apparently posing the threat.

Of course, many physical anomalies are nondiagnostic of contagion risk, for example, facial disfigurement caused by accident or violence, most physical disabilities involving movement disorders, and obesity. Nonetheless, following the smoke detector principle, perceivers overinfer and use these anomalies as heuristic indicators of risk (Park et al., 2003, 2007; Schaller \& Duncan, 2007) because reproductive fitness is generally better served by mistakenly avoiding a healthy person than by mistakenly approaching a pathogen-ridden one. Indeed, physical unattractiveness of any kind appears to serve as a crude cue for pathogen presence (Zebrowitz, Fellous, Mignault, \& Andreoletti, 2003). Thus, social perceivers view and respond to many truly healthy but superficially anomalouslooking individuals as though they were carriers of infectious disease.

The face plays a critical role in person perception given its ability to communicate functionally important information via emotional expressions and morphological features that heuristically imply the bearer's genetic relatedness or coalitional membership. The face is also where many infectious diseases leave cues to their presence in the forms of rashes, other forms of facialdiscoloration, running noses, weepy eyes, and the like. One would thus suspect that facial anomalies-even those not symptomatic of disease but heuristically viewed as such-would inspire wariness, especially among perceivers who feel vulnerable to infection. One experiment revealed that abnormal-looking faces (because they bore a port-wine stain or a misaligned eye) held a disproportionate amount of perceiver attention (relative to unblemished faces) and that this was especially the case for perceivers exposed to a slide show designed to evoke disease-avoidance concerns (Ackerman et al., 2009). Other work has shown that having had a recent illness-which actually makes a person more vulnerable to subsequent infectionalso makes one especially wary of those who exhibit heuristic cues to pathogen presence (S. L. Miller \& Maner, 2011a): People who reported recent illness (colds, flu) were more visually attentive, and exhibited stronger avoidant motor responses, to disfigured faces.

The behavioral immune system also shapes how social perceivers categorize and remember those around them. In a series of experiments focusing on obesity and old age as heuristic cues to pathogen presence, perceivers who were motivated to avoid disease-either because they dispositionally viewed themselves as vulnerable to infection or because experimental manipulations made disease threat salient-demonstrated robust disease overperception 
biases (S. L. Miller \& Maner, 2012). For example, when making quick categorization judgments, perceivers set lower thresholds for identifying target individuals as being obese rather than normal weight: They were unlikely to misperceive obese people as being of normal weight and more likely to misperceive normal-weight people as being obese. They also exhibited a leniency bias in memory, erring in the direction of recognizing obese target individuals they had not, in fact, seen before. When concerned about disease, the behavioral immune system calibrates categorization and memory processes toward making the least costly error-toward representing and remembering those presenting even heuristic cues to contagious disease as posing an infection threat rather than as not.

Other lines of research have revealed that the desire to avoid disease activates prejudices and stereotypical inferences about groups of people who possess cues heuristically implying disease. For example, people who dispositionally feel vulnerable to infection are more negative toward obese individuals, even controlling for other prejudice-relevant individual differences (Park et al., 2007). Moreover when vulnerability to infection is made temporarily salient via experimental manipulation, perceivers exaggerate their tendency to associate obese people with the concept of disease (Park et al., 2007). Ageism is also exaggerated when perceivers feel especially vulnerable to infection: Research participants who felt especially vulnerable to infection-either because of chronically high feelings of vulnerability or because the threat ofinfection was made temporarily salient-expressed higher levels of implicit ageism (Duncan \& Schaller, 2009). These findings regarding obesity and age are especially compelling demonstrations that the behavioral immune system is attuned to a broad range of morphological abnormalities that go well beyond the specific symptoms actually diagnostic of contagious disease. Obesity, for instance, was likely rare in ancestral ecologieshistorically, diseased individuals were likely underweight — and even though obesity is common in contemporary human societies it is rarely diagnostic of pathogen infection. Moreover, although elderly people's immune systems are relatively compromised, meaning that they are indeed at somewhat greater risk for acquiring and communicating disease, morphologically anomalous cues unrelated per se to risk of disease transmission-wrinkles, skin discolorations-are sufficient to engage people's disease-relevant prejudices and stereotypes. The behavioral immune system errs toward viewing morphologically abnormal individuals as diseased.

The role that disease avoidance motivation plays in prejudice may go well beyond targeting those who are morphologically abnormal to targeting individuals who apparently belong to coalitional out-groups. Members of coalitional out-groups pose many possible threats, including threats ofviolence, as we discussed earlier. They may, however, also pose threats to health via transmission of disease. For example, outsiders may be unaware of local norms related to food preparation and personal hygiene that reduce the likelihood of pathogen transmission among group members; being more likely to violate these norms, they may increase the risk of pathogen transmission within the local population. Moreover contact with exotic people increases contact with pathogens to which local individuals have not evolved immune defenses and that are thus especially virulent (e.g., it is estimated that nearly $75 \%$ of the population of what is now Mexico was decimated by pathogens brought over by Europeans in the 1500s; Dobson \& Carter, 1996). People who are subjectively perceived to be foreign are thus likely to be implicitly viewed as posing the threat of infection and so may be targeted for prejudices, especially when people are, or merely perceive themselves to be, vulnerable to infection. This is indeed the case.

For example, after viewing a slide show depicting pathogens and the threat of infection (compared with a control slide show depicting disease-irrelevant threats), participants in one experiment exhibited an exaggerated preference for immigrants from familiar places relative to immigrants from subjectively foreign parts of the world (Faulkner et al., 2004). In a similar vein, English speakers in two experiments who were dispositionally disgusted by pathogens became especially likely to perceive foreign-accented speakers of English as subjectively dissimilar when disease concerns were also made salient (Reid et al., 2012). These results demonstrate that people exhibit 
greater ethnocentrism and xenophobia when they feel vulnerable to infection. Interestingly, people also exhibit greater ethnocentrism and xenophobia when they objectively are vulnerable to infection. During the first trimester of pregnancy, a woman's body is naturally immunosuppressed (so as not to reject the fetus), creating a temporarily enhanced vulnerability to infection. Functionally adaptive responses to this vulnerability include morning sickness and greater disgust sensitivity (Fessler, Eng, \& Navarrete, 2005; Flaxman \& Sherman, 2000). This enhanced vulnerability to infection also predicts exaggerated intergroup prejudices: Women in their first trimester of pregnancy-but not in the later stages-display higher levels of xenophobia and ethnocentrism (Navarrete, Fessler, \& Eng, 2007).

If prejudices against out-group members exist partially as a defense against pathogen infection, interventions that objectively buffer people against disease — vaccinations and hand washing_might also buffer them against such prejudices. In one series of studies (Huang et al., 2011), participants for whom threats of infection were made salient exhibited negative prejudice against immigrants unless they reported having been recently vaccinated against the flu; vaccinated participants who were dispositionally concerned with disease were more prejudiced against out-groups heuristically linked with disease (e.g., people who areobese, people with physical disabilities, immigrants), but not if the infection-buffering effects of yaccination were made salient; and participants dispositionally concerned with disease were more prejudiced against out-groups heuristicallyassociated with disease but not if they washed their hands and the computer keyboard with a hând wipe before making their ratings. Interventions that reduce the risk of infection can also reduce prejudices toward groups heuristically viewed as threatening infection.

Dísease avoidance concerns also play a role in aesthetic judgments of faces. People generally prefer healthy-looking (vs. unhealthy-looking) facial complexions, but this preference emerges especially strongly among those who are dispositionally concerned about their own vulnerability to infection (Welling, Conway, DeBruine, \& Jones, 2007). Moreover, deviations from bilateral facial symmetry are associated with an individual's history of unstable physical development, infection by pathogens, and heritable genetic abnormalities (e.g., Møller \& Thornhill, 1998). Perceivers might thus use facial symmetry as a heuristic cue that others are relatively free of or resistant to pathogens and thus are relatively safe to interact with. Consistent with this, research participants from several studies who were especially concerned with disease-either dispositionally or because such concerns were experimentally activated-were also especially likely to show a preference for symmetrical faces (Little, DeBruine, \& Jones, 2011; Young, Sacco, \& Hutgenberg, 2011).

We have been discussing research revealing that the desire to avoid disease shapes how individuals perceive and think about others. Such concerns also shape how people think about themselves. For instance, circumstances that temporarily activate the threat of infectious disease lead people to view themselves as less extraverted and as less open to new experiences (Mortensen, Becker, Ackerman, Neuberg, \& Kenrick, 2010). By viewing oneself as more introverted and less interested in novelty, one becomes less likely to enter into social encounters with unknown, and potentially pathogenic, people. Such effects replicate at the cultural level, with people living in regions of the world with higher pathogen loads reporting greater dispositional leanings away from extraversion and openness to experience (Schaller \& Murray, 2008).

In sum, it is clear that a motivation to avoid disease shapes a wide range of social-cognitive phenomena. It is worth making two additional points. An evolutionary approach to social cognition often brings to bear theoretical constructs and generates predictions that lie well beyond the theoretical architectures of traditional theories. A nice illustration of this is the finding that women during their first trimester of pregnancy-but not the later trimesters-express greater ethnocentrism and xenophobia (Navarrete et al., 2007). None of the predominant approaches to prejudice-focusing as they do on processes of social categorization, social identity, realistic conflict, and the like-can generate such a prediction, even though it is readily derived within an evolutionary framework. More broadly, the breadth and richness of findings linking 
disease concerns and social cognition illustrate the generative utility of taking an evolutionary approach to understanding social cognition, because there was virtually no work on this particular motivational system and its implications for everyday thought until researchers began to explicitly apply the logical tools of evolutionary psychology.

\section{Resource Acquisition}

To reproduce successfully and have one's offspring do so as well, one must acquire sufficient tangible resources-nutrition, water, and the like. Our ancestors whose perceptual and cognitive systems were better attuned to the availability of such resources, and in ways that enhanced their likelihood of acquiring them, reproduced more successfully than their counterparts. Via natural selection, then, one would expect that contemporary humans would be equipped with cognitive resource-acquisition mechanisms. Of course, as we have noted, focusing cognitive efforts on resource acquisition comes at the cost of not attending to other important fundamental goals. Thus, just as self-protective and disease avoidance goals and their accompanying perceptual and cognitive strategies are engaged primarily when cues to danger and disease are satient, respectively (and especially for individuals who are dispositionally concerned about dangerand disease), so too would we predict that resource acquisition goals and their accompanying perceptual and cognitive strategies would be engaged primarily when cues to resource deprivation are salient (and especially for those who are dispositionally concerned about resource scarcity).

Indeed, a line of research stretching back to the days of the New Look (Bruner, 1957) has provided evidence for how the deprivation of certain resources alters how people perceive functionally related stimuli. Poor children were observed to see conns as larger than they really were (Bruner \& Goodman, 1947), for example, and hungry people perceived pictures of food to be brighter than they really were (Gilchrist \& Nesberg, 1952).

More recently, a set of studies demonstrated that making people thirsty activates in the mind drinking-related concepts and makes drinking-related items more memorable (Aarts, Dijksterhuis, \& De
Vries, 2001): Compared with research participants who had consumed regular candies, those who had consumed salty versions of those candies responded more quickly in a lexical decision task to drinkingrelated items (relative to drinking unrelated items). Moreover, thirsty participants in a second study exhibited enhanced incidental memory for drinkingrelevant objects (relative to drinking-unrelated objects) that had been placed in the lab environment. Other work has demonstrated that hungry people are better able than satiated people to learn and remember food-related words (Epstein \& Levitt, 1962). Such biases can emerge ar the earliest stages of perceptual encoding: Hungry experimental participants gained earlier conseious access to rapidly presented food-related words than did satiated people (Radel \& Clément-Guillotin, 2012). As in the experiments discussed earlier, in which the thirstinduced processing advantages did not emerge for drinking-unrelated items, the hunger-induced learning and perceptual advantages did not emerge forfood-unrelated words. The motivations engaged by hunger and thirst do not lead to domain-general processing advantages but rather are functionally focused in a domain-specific manner.

In addition to those biases, people also perceive currently desired resources to be physically closer (Balcetis \& Dunning, 2010): Thirsty people (but not nonthirsty people) perceived water bottles in their proximity to be closer, and people perceived a $\$ 100$ bill they could win to be physically closer than a $\$ 100$ bill they could not win. In all, the reviewed research reveals that the motivation to acquire tangible, survival-relevant resources-in these cases, induced via hunger, thirst, and the opportunity to win significant money-creates a set of perceptual and cognitive biases functioning to increase the likelihood that a person will obtain the resources. These biases not only divert people toward prioritizing the acquisition of these resources (e.g., via increased cognitive accessibility of the resource concepts) and make people more aware that such resources exist in their immediate environment (e.g., via enhancing their ability to identify and remember them), but they also make the desired resource seem relatively easy to attain (e.g., by making them appear physically closer). 
Informed by life history theory (e.g., Stearns, 1992), other work has focused on how and when people allocate limited resources to different life tasks (e.g., physical growth, mating, parenting) and on the strategies they use to acquire resources (Figueredo et al., 2006; K. Hill \& Kaplan, 1999; Kenrick \& Keefe, 1992; Kenrick \& Luce, 2000). For humans and other animals, the strategies driving these behaviors are shaped by an individual's current and early developmental ecologies. Harsh and unpredictable ecologies shorten life spans and are thus associated with a suite of "fast" strategic behaviors that move people more quickly from investing energy in growing their physical and human capital to investing energy and effort in mating; in contrast, ecologies that are more resource rich and predictable are associated with a "slow" suite of strategic behaviors in which people put off investment in mating for continued further growth and capacity building (Ellis, Figueredo, Brumbach, \& Schlomer, 2009). For example, relative to resource-rich and predictable environments, harsh and unpredictable ecologies pull for earlier menarche for girls, greater promiscuity, having more children, risk taking, impulsivity, and antisocial behavior including violence and criminality (Brumbach, Figueredo, \& Ellis, 2009; Figueredo et al., 2005, 2006).

Recent research has shown that having been reared in harsh and unpredictable envirønments as a young child steers one to engage in fast strategies in response to perceived resource stress/ater in life, whereas having been reared in more well-off and more predictable environments steers one to engage in slower strategies in response to perceived resource stress later intife (Griskevicius, Delton, Robertson, \& Tybûr, 2011; Simpson, Griskevicius, Kuo, Sung, \& Collins, 2012). For example, after having economic insecurity primed (via photographs highlighting economic recession), people with low-socioconomic-status childhoods are especially likely'to discount the future (by accepting smaller, immediate rewards rather than larger rewards in the future) and to prefer riskier rather than safer current rewards (by preferring low-probability large rewards to smaller sure bets). In contrast, people who had high-socioconomic-status childhoods responded to the primes of economic recession in the opposite manner-by being willing to delay immediate rewards for larger future ones and by taking current rewards that are certain rather than gamble for larger ones (Griskevicius et al., 2013; see also Griskevicius, Tybur, Delton, \& Robertson, 2011).

Other processes may be recruited in the service of attaining and protecting important resources. For example, college students assigned to read a news story about economic downturns and difficult job. markets expressed increased prejudice against Asian Americans-a group stereotyped as posing threats to those seeking good jobs (Butz \& Yogeeswaran, 2011). Following from research discussed earlier on the threat specificity of intergroup prejudices (Cottrell $\&$ Neuberg, 2005; Schaller \& Neuberg, 2012), it is instructive to note the presence of one of the hallmarks of evolved processes-functional specificity. In this experiment, prejudice against Asian Americans did not inerease after a manipulation of a threat not presented as economic (i.e., global warming), and actiyating resource concerns did not increase prejudice ágainst all out-groups (i.e., against Black Americans, who are stereotyped as threatening but not in an economic way).

The Butz and Yogeeswaran (2011) study demonstrated that concern about resources can engage prejudice processes. Other work has shown how similar concerns alter mating psychology. For example, news stories that activate economic concern increase women's preference for financially secure men and, in turn, their willingness to spend on beauty-enhancing products they view as useful for attracting such men-the so-called "lipstick effect" (S. E. Hill, Rodeheffer, Griskevicius, Durante, \& White, 2012). Revealing functional specificity, this effect was not observed for products viewed as irrelevant to attracting men with resources. Moreover, other findings revealed that the effect was not driven by the women's current need for resources. Rather, the effect appeared to be rooted in a deeper female mating psychology that desires long-term partners who can provide resource stability: Recognizing that difficult economic times reduce the current availability of such men, even currently secure college women may have felt compelled to enhance their physical attractiveness to be competitive in this more challenging long-term mating market. 
As with goals related to self-protection and disease avoidance, then, activated concerns about acquiring resources also meaningfully shape cognitive processing in functionally focused, nuanced ways.

\section{Social Affiliation}

Ultrasociality is among the most important of human adaptations: Relative to our more solitary ancestors, those humans who successfully pursued cooperative, highly interdependent group living received significant fitness advantages via sharing of nutrition and other resources, protection against predators, rearing of children, and the like (e.g., Brewer \& Caporael, 2006; D. Campbell, 1982; Leakey \& Lewin, 1977; Richerson \& Boyd, 1995). Given such critical benefits, humans evolved to seek acceptance from group members-to possess a strong need to belong (Baumeister \& Leary, 1995). When that need is not satisfied-when social acceptance is in doubt, or after one has been socially rejected-people do as one might expect: They exhibit increased desires to connect with those who appear to pose potentially good opportunities for friendship (Bernstein, Sacco, Brown, Young, \& Claypool, 2010; Maner, DeWall, et al., 2007). That social rejection is powerfully motivating is further reflected in some of its neurological concomitants. For people with dispositional inclinations to reconnect (rather than withdraw) after rejection, social rejection increases progesterone - hormone associated with, and perhaps facilitative of, affiliative motivation (Maner, Miller, Schmidt, \& Eckel, 2010). Moreover, social rejection exploits the same brain systems that evolved to experience and manage physical pain (as part of an effort to ward against additional physical injury and to facilitate healing) to also experience and manage social pain (as part of an effort to ward against additional social rejection and tôfacilitate social connection; Eisenberger, Lieberman, \&. Williams, 2003; MacDonald \& Leary, 2005).

A range of cognitive mechanisms play important functional roles in helping people both avoid social rejection and successfully reconnect with others after rejection. For example, when concerned about social acceptance and rejection, social perceivers become especially good at discriminating among potentially accepting versus rejecting faces. Individuals who dispositionally have a greater need to belong are better at discriminating between happy and angry faces-an important sensitivity given that those bearing happy expressions are likely to be more socially accepting than those bearing angry expressions (Pickett, Gardner, \& Knowles, 2004). More telling is experimental work by Bernstein, Young, Brown, Sacco, and Claypool (2008) in which perceivers randomly assigned to write about a time they felt rejected, about a time they fett accepted, or about their previous morning (control) had the task of discriminating between authentic smiles and inauthentic smiles. The researchers reasoned that, for those concerned with sodial rejection, being able to differentiate between true and faked smiles should be particularly important because those expressing truesmiles more strongly afford social acceptance. This is indeed what they found (Bernstein et al., 2008).

In addition to this enhanced perceptual sensitivity, individuals threatened with social exclusion exhibit attentional selectivity biased toward potentially accepting others. In one set of experiments, socially excluded participants were especially likely to attend to smiling faces: They were quicker to identify smiling faces embedded among other faces, they fixated their attention more on smiling faces, and they were slower to disengage their attention from smiling faces (DeWall, Maner, \& Rouby, 2009). More important, these effects were specific to approving faces: They did not obtain for disapproving faces or for positive, but nonsocial, stimuli. Apparently, the threat of social exclusion motivated individuals, at very early stages of cognitive processing, to attempt to connect with faces presenting cues (i.e., smiles) linked to social acceptance.

Concerns about social exclusion also shape inference processes. In one experiment, individuals were asked to form impressions of average-looking, neutrally expressive faces; participants who had just been socially rejected by others viewed the faces as more sociable (nicer, more friendly) than did those who learned they had just been socially accepted (Maner, DeWall, et al., 2007). In the absence of cues to social threat-the faces in this experiment posed neutral expressions-a positivity bias in impression 
formation likely functions to make it easier for rejected individuals to approach potentially accepting others.

Whereas the experience of social rejection leads people to shift cognitive processes toward solving the problem of social connection, the experience of social acceptance apparently frees one to seek other fundamental goals. Life history theory aims to explain how organisms allocate energy and time to different tasks across the life span (Kaplan \& Gangestad, 2005; Stearns, 1976). Starting with the premise that resources are finite, organisms face the problem of how to allocate them to maximize reproductive fitness. When one is socially accepted, one can shift resources toward pursuing other goals, such as reproduction. Indeed, whether after actual social acceptance or after remembering instances of social acceptance, people reported an increased interest in, and importance of, mating (Brown, Young, Sacco, Bernstein, \& Claypool, 2009).

In sum, fundamental desires to be socially accepted (and to avoid social rejection) shape a wide range of cognitive processes-and do so in nuanced, functionally specific ways.

\section{STATUS AND DOMINANCE SEEKING}

Although evolved to be affiliative and ultrasocial, humans are also selfish and, like other animals, seek opportunities to enhance themselves relative to others-to seek status. Status canderive from one's ability and willingness to physically dominate others. It can also derive fromone's ability and willingness to manage a network of social connections to control the benefits others receive. Also, unlike the status gained via physical dominance and social power, which tends to be conferred grudgingly by others, a thind form of status-prestige-can derive from the possession of important and unique knowledge or skills that others desire to learn (Henrich \& Gil-White, 2001).

Regardless of its source, high status affords significant fitness-enhancing benefits for those with it. Possessing high status means that others are more likely to defer to claims for resources, to perform favors, and-for male holders of high status, especially—to make themselves available for mating
(N. P. Li \& Kenrick, 2006; Sadalla, Kenrick, \& Vershure, 1987; Turke \& Betzig, 1985). It is thus clear why people would desire status, attend to possibilities for seeking it, and be attuned to existing status relationships and changes in them.

When available cues suggest that one has status, one's psychology and physiology orient in apparent preparation to take advantage of the opportunities often afforded by it. For example, status and power are typically displayed in human and nonhuman animals with open, expansive postures, whereas acknowledgments of low power tend to be displayed with closed, tight postures. In one experiment, participants were positioned by researchers to display a high-power (vs. low-power) pose; consequently, they felt more powerful, exhibited an increased level of testosterone (a hormane linked to competitiveness) and a decreased level of cortisol (a hormone linked to stress), and took greater risks on a gambling task (Carney, Cuddy, \& Yap, 2010).

People cognitively process information about status available in the form of social hierarchies with relative ease, being especially quick to identify, learn, and remember such hierarchies (Zitek \& Tiedens, 2012). The ability and inclination to mentally represent hierarchical relations between others emerges at a very young age, 12-15 months (Mascaro \& Csibra, 2012). Moreover, in line with the fact that high-status individuals (compared with lower status counterparts) potentially pose significant threats to and opportunities for others, people cognitively process high-status others in privileged ways. For instance, compared with faces labeled as belonging to low-status individuals, faces of highstatus individuals capture more attention, are remembered better, and are processed using more effective holistic strategies (Ratcliff, Hugenberg, Shriver, \& Bernstein, 2011). Other research has shown enhanced attentional processing for highstatus men in particular (e.g., DeWall \& Maner, 2008; Maner, DeWall, \& Gaillot, 2008). This sex difference comports with theory and a great amount of evidence that dominant males ought to be of special interest-to female perceivers because dominant men are desirable as mates (e.g., N. P. Li, Bailey, Kenrick, \& Linsenmeier, 2002; Sadalla et al, 1987) and to male perceivers because dominant men afford 
significant intrasexual competition (e.g., Buss \& Schmidt, 1993; Maner, Gailliot, Rouby, \& Miller, 2007). Although it is clear that high-status individuals receive privileged cognitive processing, the circumstances under which target sex differences emerge remains an open question.

Strategic processing of high-status individuals should be especially pronounced for perceivers who are dispositionally or acutely concerned with status and dominance. Perceivers high in social dominance orientation (Pratto, Sidanius, Stallworth, \& Malle, 1994) view status as a central organizing feature of social life and prefer hierarchical relations among people and groups. One might thus expect them to be particularly attuned to high-status individuals, especially those with the potential and inclination to project their status into social relations-such as angry, high-status men. Consistent with this, one study found that perceivers high in social dominance orientation were generally better than those low in social dominance orientation at identifying emotional expressions on high-status male faces and that this was especially the case when the target faces were angry high-status men (Ratcliff, Bernstein, Cundiff, \& Vescio, 2012).

Other work has focused on envy-an emotion that results from social comparisons with advantaged others. Envy often motivates status-relevant inclinations toward ambition (to enhance orre's own status), destruction (to take down another's high status), or submission (to accept and defer to another's high status; S. E. Hill \& Buss, 2008; van de Ven, Zeelenberg, \& Pieters, 2009). S. E.Hill, DelPriore, and Vaughan (2011) reasoned that, when envious, one might be especially inclined to gather information about those who are relatively advantaged because such information might be useful for determining how to become advantaged oneself, how best to damage another's status, or whether to defer to another's status. Indeed, participants led to experience envy attended more to information about their advantaged peers and remembered more about them.

\section{Mate Acquisition}

For humans, as for all sexually reproducing animals, acquiring a desirable mate is a central challenge. Indeed, the evolutionary literature on mating-seeking psychology is vast, and this chapter is not designed to provide a review of it. Earlier, we introduced several key principles and illustrative empirical findings (e.g., differential parental investment and its implications for sex differences in the characteristics males and females prefer in mates) when summarizing the logical foundations of evolutionary social cognition. Here we focus on how the activation of a mate-seeking goal shapes social cognition in functionally nuanced ways.

Men, especially when they are in a mating frame of mind, selectively attune their attention to attractive women, pay extra attention to them, and have a relatively difficult time disengaging attention from them (Duncan et al., 2007, Maner, Gailliot, \& DeWall, 2007; Maner, Gailliot, Rouby, \& Miller, 2007; Maner et al, 2003). Indicative of their functional specificity these mate-seeking effects are less likely to emerge for men who are dispositionally restricted in their sexuality - those who are especially oriented toward long-term committed relationships. These attentional biases also tend to be directed specifically toward attractive women but not average-looking women, and not toward attractive people in general (i.e., attractive men). Moreover, memory for attractive women-good under normal motivational circumstances (e.g., Becker, Kenrick, Guerin, \& Maner, 2005)_is further enhanced when men are in a mating frame of mind (Maner et al., 2003).

Mating-minded women-either because they are dispositionally sexually unrestricted, have recently been exposed to circumstances that activate mating goals, or are currently ovulating-devote increased attention to attractive men (Anderson et al., 2010; Becker et al., 2005; Maner et al., 2003; Maner, Gailliot, Rouby, \& Miller, 2007). Interestingly, however, this boost in attention does not tend to translate into enhanced memory, revealing a processing disjunction. As a general principle, enhanced visual attention typically translates into enhanced memory. When it does not-and when the disruption in memory encoding cannot be readily attributed to cognitive overload, distraction, or interference from competing stimuli-it is worth considering the possibility that the social-cognitive system may be calibrated to the functional value provided by different processes 
in the cognitive stream. In this case, whereas there may be value for mating-minded women to scan initially for physically attractive men and pay some degree of enhanced attention to them, the costs for women of short-term sexual liaisons remain great (e.g., unwanted pregnancy). Extensive processing of attractive male strangers-in the absence of cues suggesting that they possess other desirable features (e.g., resources, willingness to commit)—may thus generally be a poor use of limited cognitive resources (Kenrick, Delton, Robertson, Becker, \& Neuberg, 2007). Similar functionally directed processing disjunctions-in which enhanced attention does not translate into enhanced memory-have been observed in the context of disease-avoidant perceivers processing information about individuals presenting invariant cues of infectious disease (Ackerman et al., 2009).

From an evolutionary perspective, the costs for men of perceiving a good mating opportunity that does not actually exist are less than the costs of missing a good mating opportunity that does exist: In the first case, the misperception carries the possible cost of social rejection and wasted effort; in the latter case, the misperception costs a scarce, and highly valuable, opportunity (Haselton \& Buss, 2000; Haselton \& Nettle, 2006). A bias toward overperceiving female sexual interest, then, would serve to encourage men to pursue mating oppørtunities they might otherwise let pass, thereby increasing their overall likelihood of success. Indeed, men do tend to overperceive female sexual interest (e.g., Abbey, 1982; Farris, Treat, Jiken, \& McFall, 2008; Henningsen, Henningsen, \& Valde, 2006). Revealing the functional specificity of this bias, it tends to be directed toward physically attractive womenwho pose, for most men, the greatest mating challenge but also the greatest reproductive value. This bias is also strongest for men in a mating frame of mind, either because of recent circumstances or because of dispositional sexual unrestrictedness (Maner et al., 2005; Perilloux, Easton, \& Buss, 2012). Of course, for women, the costs of pursuing sexual relationships with male strangers are greater, and-with the exception of circumstances in which women are in a clear power position over a man (Kunstman \& Maner, 2011)_they exhibit little evidence of overperceiving male sexual interest (e.g., Haselton \& Buss, 2000) and may even underestimate male interest (Perilloux et al., 2012).

When ovulating, women's partner preferences shift toward men with characteristics implying masculinity and good genes (for reviews, see DeBruine et al., 2010; Gangestad \& Thornhill, 2008; B. C. Jones et al., 2008). Ovulation also has more general effects in cognitively orienting women toward partners presumed to be more suitable mates. Compared with nonovulating women, ovulating women are quicker to categorize male than female faces (Johnston, Arden, Macrae, \& Grace, 2003; Macrae, Alnwick, Milne, \&/Sehloerscheidt, 2002). Women close to their peak ovulation are also better able to differentiate between the faces of selfidentified straight and gay men (Rule, Rosen, Slepian, \& Ambady, 2011). This enhanced ability to differentiate is not attributable to a general improvement in socialperception accuracy; ovulating women are no better at differentiating between straight and lesbian women. Rather, these findings suggest, again, the presence of a cognitive mechanism tuned toward solving a mating-related challenge (i.e., identifying a suitable mate) when it especially makes functional sense to do so (i.e., when ovulating).

Interestingly, women's ovulation status also shapes male mate-seeking motivation and cognition. Men expend great effort and resources seeking mates. All else equal, our male ancestors who were attuned to female peak fertility, and consequently focused their mating efforts and resources at that time, would have gained a significant reproductive advantage over their less attuned counterparts, which suggests the possibility of male adaptations for identifying female peak fertility-even if nonconsciously-and for enhancing mating motivation in response. Indeed, there exist detectable cues to ovulation in women's behavior, scent, and voice (for a review, see Haselton \& Gildersleeve, 2011). Moreover, men demonstrate behavioral, hormonal, and cognitive shifts in response to women's approaching ovulation. For example, men exposed to T-shirts worn by women near (vs. far from) ovulation exhibit higher levels of testosterone (S. L. Miller $\&$ Maner, 2010b) — a hormone linked to mating motivation (Roney, Lukaszewski, \& Simmons, 2007). 
Such men also exhibit increased accessibility of sexual thoughts and exhibit greater nonverbal mimicry and riskier decisions - each of which have also been linked to mating motivation-when interacting with women near the time of ovulation (S. L. Miller \& Maner, 2011b). Male mating motivation, like women's, is responsive to female hormonal fluctuations.

Mate-seeking motivation also shapes economic decision making (Kenrick et al., 2009). Consider, for instance, the phenomenon of loss aversion, in which people psychologically weigh losses more heavily than equivalent gains (Kahneman \& Tversky, 1979; Tversky \& Kahneman, 1991). This bias is highly robust (Vohs \& Luce, 2010) and, given that our ancestors operated near the economic margins in ecological contexts of scarcity and unpredictability, there are good reasons to view it as an adaptation designed to preserve valuable resources. As we have noted, however, adaptations are functionally flexible, sensitive to the individual's life history and immediate circumstances. For men, access to sexually available women was also scarce, and so risking existing resources to acquire potentially greater resources (because women value resources in a mate) or to signal that one could afford to take such risks (which also implies enhanced male mate value) may have been an effective strategy when mating motivation was especially salient and strong. Indeed, in a series of experiments, men-but not women-became biased away from loss aversion and toward gain seeking when mate-seeking goals were activated (Y. J. Li, Kenrick, Griskevicius, \& Neuberg, 2012). Note that men did not become more gain seeking when self-protection goals were activated, revealing again the functional specificity of many cognitive biases.

\section{Mate Retention}

To manage the complexities of interdependent ultrasociality effectively, human adults must possess nuanced social skills and strategies, as well as a large amount of social information. To accommodate the required learning, children take a relatively long time to sexually mature into adults. This lengthy developmental period requires enhanced and extended parental investment, which is itself facilitated by long-term pair bonding of parents.
As with all adaptations, however, pair-bonded mating involves trade-offs. Exclusive pair bonding requires abstention from extrapair mating opportunities. For men, extrapair mating increases the number of offspring they can produce; for women, selective extrapair mating can increase the genetic quality of their offspring. Extrapair mating thus affords certain benefits for the self. Despite such benefits, extrapair mating can also impose great costs on one's partner. Men who mate outside the pair bond may, via the link between love and investment, redirect resources away from the pair-bonded mate and her children. Womenwho mate outside the pair bond may become impregnated, leading to the possibility that the cuckolded pair-bonded mate will unwittingly invest scarce resources in children fathered by another. In response, humans apparently evolved mechanisms designed to limit extrapair mating by partners, as well as to address other challenges to mate retention (e.g., Buss $\&$ Shackelford, 1997a; Haselton \& Gangestad, 2006).

The costs of extrapair mating are somewhat different for men and women. One might thus expect men and women to use somewhat different strategies to combat it in their partners. Much research, for instance, has focused on jealousy. This work has found that, consistent with this reasoning, men tend to be especially jealous of the possibility that their mates may have sex with other men, whereas women tend to be especially jealous of the possibility that their mates may fall in love with another woman (Buss et al., 1992; B. P. Buunk, Angleitner, Obaid, \& Buss, 1996; Pietrzak, Laird, Stevens, \& Thompson, 2002; Sagarin, Becker, Guadagno, Nicastle, \& Millevoi, 2003; Shackelford, LeBlanc, \& Drass, 2000; Wiederman \& Allgeier, 1992; for reviews, see Buss, 2004; Sagarin, 2005).

Here we focus on social-cognitive processes that facilitate mate retention and see that they are especially likely to be used under circumstances in which infidelity concerns are salient. Consider, for example, how mate-retention motivation might modulate early categorization processes. Members of one's own sex are potential competitors for one's current partner; if same-sex competitors are physically attractive, and thereby particularly desirable for short-term mating, they are a greater threat. 
Thus, if one is particularly invested in one's relationship or is acutely concerned that one's partner may be interested in an extrapair relationship, one should be more likely to encode others in terms of their physical attractiveness. This is the case (Maner et al., 2012): Participants in one study who were highly invested in their current relationships were especially likely to categorize same-sex individuals in terms of their physical attractiveness; this was not the case for those who were less invested in their relationships_-unless they had been asked to imagine their partner flirting with and kissing someone else at a party. Whether concern for mate retention was based on previous relationship investment or on an acute contemplation that one's partner might sexually cheat, it shaped the dimension used-physical attractiveness - to categorize others.

We showed earlier that men pay special attention to physically attractive women and remember them well. Women, too, pay special attention to, and remember well, physically attractive women. This latter finding may be linked to mate-retention concerns because the bias seems to be especially strong for women committed to their current relationships (Maner et al., 2003). Other work has shown that, for individuals who are dispositionally vigilant to same sex competitors, having them visualize a partner flirting with and kissing another person increased their attention to attractive same-sex others. Demonstrating functional specificity, this attentional bias was not observed in a control condition manipulating general anxiety for perceivers dispositionally unconcerned about being cheated on when the same-sex targets were only average looking or when the targets were of the opposite sex (Maner, Gailliot, Rouby, \& Miller, 2007). Other findings have further suggested the goal-focused nature of this enhanced attention to same-sex others: The attention of women who are insecure about their current relationships is especially captured by other attractive women (Maner, Gailliot, \& DeWall, 2007).

Cognitive processing focused on potential romantic competitors goes beyond attention. For perceivers who are chronically jealous, activating concerns about a partner's infidelity also increases the effectiveness with which one encodes and remembers physically attractive strangers of the same sex and facilitates the forming of implicit negative evaluations of them (Maner, Miller, Rouby, \& Gailliot, 2009). In all, the data reveal the presence of a suite of functionally tuned cognitive mechanisms that serve to protect against threats from potential romantic competitors.

Focusing on potential competitors is one strategy for mate retention. A second is to enhance one's own commitment-or at least one's apparent commitment-to one's partner, thereby reducing the relative benefits to them of seeking extrapair mates. This is no simple feat, because the presence of desirable members of the opposite sex can reduce commitment to one's own relationship (e.g., Kenrick, Neuberg, Zierk, \& Krones, 1994). Yet the benefits of maintaining a pair-bonded relationship are also great, and it appears that eertain psychological inclinations are in place to do just that. Perhaps most notable is the inclination for relationship-committed people to see otherwise desirable others as, in fact, less desirable (e.g., S. L. Miller \& Maner, 2010a; Simpson, Gangestad, \& Lerma, 1990). Moreover, whereas early attention of mating-minded individuals is generally drawn and held by attractive opposite-sex targets, the same activated mating goals decrease the attentional pull of attractive opposite-sex targets for individuals who view themselves as highly committed to a current romantic partner (Maner, Gailliot, $\&$ Miller, 2009).

Such effects may be mediated by the emotion of love, which appears to serve as a relationship commitment mechanism (Gonzaga, Keltner, Londahl, \& Smith, 2001). Consistent with this idea, the experience of love is linked with oxytocin, a hormone designed to facilitate social bonding among human and nonhuman individuals (Taylor et al., 2000). Moreover, feelings of love make it easier for people to suppress thoughts of physically attractive alternatives to their current partners (Gonzaga, Haselton, Smurda, Davies, \& Poore, 2008). In another experiment, participants in committed romantic relationships were assigned to write about a time they felt strongly in love with their current partner; control participants (also in committed relationships) wrote instead about a time they felt very happy. A subsequent task assessing attention to physically attractive opposite-sex targets revealed that, when love for 
partners had been made salient, the physically attractive potential romantic alternatives were less likely to hold participants' attention (Maner, Rouby, \& Gonzaga, 2008).

\section{Child Rearing and Kin Care}

As just discussed, human young require-and generally receive-great amounts of parental care (Geary, 2000). Such care is not indiscriminate, however. The motivation to provide care depends partially on the genetic payoff (Kurland \& Gaulin, 2005; Salmon, 2005). For instance, in line with differences in genetic relatedness, parents nurture their biological offspring more than their stepchildren (Daly \& Wilson, 1998; Tooley, Karakis, Stokes, \& OzanneSmith, 2006). Following from our discussion of paternal uncertainty and cuckoldry, fathers provide better care for children who look like them-a cue that heuristically implies genetic relatedness - than for those who do not (Apicella \& Marlowe, 2004; Burch \& Gallup, 2000; Platek et al., 2004). And paternal grandfathers-who can never be certain whether their own sons are actually theirs or whether their son's children are actually his-are generally less likely to invest in these grandchildren (Laham Gonsalkorale, \& von Hippel, 2005; Michalski \& Shackelford, 2005; Pollet, Nettle, \& Nelissen, 2007 ; Webster, 2003).

The motivation for parents to provide care is also partially shaped by a child's likelihood of surviving to successfully reproduce. After all, with limited resources parents are faced with trade-offs-between caring for one child versus another and between caring for a child versus investing in additional reproduction. Indeed, mothers tend to invest more in children who are healthy than in those who are not (Hrdy, 1999).

These findings focus on the provision of resources and prosocial action. There is, at present, a relative paucity of empirical research that directly explores the ways in which the activation of parental care goals shapes social cognition. One study investigated the effects that subtly priming women with a parenting goal would have on their reactions to potentially disgusting images-some of which were related to child rearing (e.g., photos of babies with runny noses or dirty diapers) and some of which were not (e.g., photos of ugly animals, dirty toilets). Disgust motivates avoidance, yet raising young children requires one to confront much that is disgusting. One might hypothesize that, when concerned about parenting, the subjective experience of child-elicited disgust would be attenuated so that one could remain engaged and able to effectively care for the child. Supporting this hypothesis, women who were primed with a parenting goal (compared with control participants) and who were also in the fertile stage of their menstrual cycle (and thats at a time when conception is most likely) were less disgusted by the gross baby images (Shidloyski \& Hassin, 2011). Suggesting functional specificity, this attenuated disgust response was limited to the baby stimuli: Ovulating parenting-minded women were as disgusted by the nonbaby stimuli as were the other women.

Several other experiments have temporarily activated a parental mind-set-and thus activated fundamental goals specific to parental care and child rearing-by reminding parents that they are, in fact, parents. Given that a substantial fitness benefit of parental care accrues from the protection of offspring from health risks of various kinds, one might expect that this kind of manipulation might influence risk-relevant cognitions. It does. When parents are reminded of their parenthood, they consequently judge potentially risky activities (e.g., skiing) to be more risky, they engage in more risk-averse economic decision making, and they respond more harshly to morally offensive violations of behavioral norms (Eibach, Libby, \& Ehrlinger, 2009; Eibach \& Mock, 2011). These results in the cognitive realm are conceptually consistent with results from other experiments (that use different methods that temporarily create a parental mind-set characterized by feelings of tenderness toward infants), indicating temporary decreases in testosterone levels and more careful and cautious motor behavior (Sherman, Haidt, \& Coan, 2009). The conceptual coherence of these various results reminds us, once again, that thinking is for doing - that the effects of fundamental motives on social cognition is just one adaptive part of a physiological system that evolved in service to fitnessrelevant behavior. 
One might further expect that parenting-focused individuals would exhibit other functional biases as well. For example, they may be especially attuned to signals (e.g., cries) that their children are in need, be especially good at differentiating their children from similar others (visually, aurally, and by smell; e.g., Wiesenfeld, Malatesta, \& Deloach, 1981), have especially good memory for their children's last known location, remember especially well functionally relevant details about their children's lives, be particularly attentive to their children's potential mates (e.g., A. P. Buunk et al., 2008; Faulkner \& Schaller, 2007; Perilloux, Fleischman, \& Buss, 2008), and the like. Moreover, such effects may be moderated by the children's own reproductive value to the parent. Such hypotheses remain to be thoroughly explored.

The concept of inclusive fitness recognizes that our genes reside not just in the bodies of our offspring but in others' bodies as well (Hamilton, 1964a, 1964b). Thus, by enhancing the reproductive fitness of those who are close genetic relatives, we potentially enhance our own fitness, too. This explains strong psychological inclinations toward nepotism-in humans and other animals_-as well as the enhanced inclination to help close kin, especially when their fitness is threatened (e.g., Burnstein et al., 1994; see Burnstein, 2005, for a review). Because people have no means of directly) assessing others' genetic relatedness, people iroplicitly use imperfect superficial cues as impticit indicators of kinship. One such cue is familiarity: Ancestrally, people would have been, on average, in closer physical proximity to family members than to more genetically distar individuals. Another cue is phenotypic resemblance: Given that phenotypic features are substantially influenced by genes, people whoare more closely related genetically tend to be more similar in physical appearance, attitudes, and behavior. As we discussed earlier, extensive bodies of research now reveal that people do indeed attend to these kinds of cues and use them to draw implicit inferences about kinship, with predictable implications for person perception and social judgment (DeBruine, 2005; Lieberman et al., 2007; Park \& Schaller, 2005; Park et al., 2007).
Although we know of no research that has explicitly attempted to experimentally activate kin care goals in a manner analogous to the methods of manipulating self-protection, mate retention, and other fundamental human motives, it seems a worthwhile endeavor for future research. Such goal states, when activated, may have predictable implications for the manner in which heuristic cues (such as facial similarity) implicitly connote kinship and for a wide range of downstream cognitive consequences that follow from kinship inferences (inferences about trustworthiness, sexual attractiveness, etc.).

More generally, we see that whereas the adaptive cognitive consequences of some fundamental motives (such as self-protection) have been illuminated in considerable detail, the cognitive consequences of others (mate retention, child rearing, kin care) have yet to receive the same level of empirical attention. The broad principles discussed throughout this chapter may be useful in developing these programs of research further.

\section{SOCIAL COGNITION AS AFFORDANCE MÁNAGEMENT}

From an evolutionary approach, social cognition is a set of tools for managing the threats and opportunities afforded by others in one's social environment. These tools do not exist to enhance self-regardalthough they sometimes do. They do not exist to discover or attribute meaning to life-although they sometimes do. They do not exist merely to simplify an awesomely complex and dynamic worldalthough they certainly do. And they do not exist to provide perfect assessments of that world-which they certainly do not. Rather, these tools exist as specialized mechanisms, as adaptations designed by natural selection to solve a set of long-recurring challenges to our ancestors' reproductive fitnesschallenges related to self-protection, disease avoidance, resource acquisition, social affiliation, status acquisition, mate acquisition, mate retention, child rearing, and kin care.

These cognitive mechanisms respond to stimuli that cue specific social opportunities and threats. We have seen, for example, that angry expressions cue threats to physical safety, bodily malformations 
cue the possibility of disease contagion, facial symmetry cues good genes for purposes of mating, and the like. Such cues are not promiscuously relevant: Angry facial expressions, for instance, do not cue all manner of threats, but rather a specific threat. The content of what is being processed matters. Content matters in another way, too. Whether these cues are noticed and processed, and the roles they play in downstream cognition and judgment, depends on a perceiver's current motives: For a perceiver interested in finding a short-term matewhether because she is dispositionally unrestricted sexually, because she is currently ovulating, or because the immediate social context makes such a goal particularly attractive to her-a neighbor's exquisite facial symmetry may be of some moment; for a parent attending to a sick child, that physical beauty is unlikely to register or be targeted with subsequent interest.

Such cues are imperfectly diagnostic and their use is necessarily heuristic, but they are not arbitrary. Rather, they were likely diagnostic of real threats and opportunities in our ancestral environments and thus are still used, if not consciously, today. This means that the inferences and judgments resulting from the processing of such cues will sometimes be mistakes. Angry expressions do not always reveal authentic anger, bodily abnormalities do not always reveal contagious disease, and facial symmetry (does not always reveal good genes (insert your favorite cosmetic surgery joke here). Their use, however, conferred on ancestral populations more benefits than costs, and humans are biased toward using them today. Social cognition is thus imperfect-indeed, expected to be imperfect-but inadaptively sensible ways. In our attempts to manage the threats and opportunities of social life, humans might be said to be, in an ancestral sense, deeply rational (Kenrick et al., 2009).

\section{NATURE AND NURTURE}

We noted earlier that evolutionary approaches to human cognition and behavior are all too frequently interpreted as implying a hard-wired, genetic determinism that leaves little room for developmental, learning, and cultural influences. We also noted that this interpretation is a gross misconstrual.
Development is critical to evolutionary approaches. How genes are expressed depends on a wide range of factors, including gestational hormones and early childhood environments. This phenotypic plasticity is not only presumed by an evolutionary approach but also viewed as adaptive, because the ability of any evolved inclination to benefit the individual depends on the local environment. As discussed earlier, individual differences in fast versus slow life history strategies, emerging as a function of the levels of harshness and predictability of childhood environments, provide but one example.

Learning is also critical to evolutionary approaches. It enables people to acquire information about local circumstances, thereby enabling them to flexibly - and functionally — prioritize their goals and adjust their actions to better serve them. We discussed the idea of prepared learning, in which people are better equipped to learn, and not to unlearn, evolutionarily relevant versus irrelevant associations (e.g., to fear snakes vs. electrical outlets, to fear out-group men vs. out-group women; Ôhman \& Mineka, 2001; Navarrete et al., 2009).

This is not to say that humans are not entirely capable of learning things totally irrelevant to ancestral priorities. Of course they are, and they do. It is to say, however, that the mind is not a blank slate and that some things are predictably easier to learn, and remember, than are others (Pinker, 2003).

Cultural influences are therefore entirely compatible with an evolutionary approach to social cognition, as is cultural variability. Such influences emerge because cultural contexts afford somewhat different nuances of threats and opportunities, somewhat different developmental contexts, and somewhat different learning environments and, indeed, things to learn. We would thus expect even evolved, universal mechanisms to manifest themselves somewhat differently across cultures (Norenzayan, Schaller, \& Heine, 2010).

From an evolutionary psychology view, it is long past time to abandon the simplistic, wrong-headed, and wearying nature-versus-nurture discussion. Evolutionary explanations and developmental, learning, and sociocultural explanations are not alternatives for explaining human cognition and behavior. Rather, these forces interact with one 
another in complex and interesting ways. The pursuit of understanding these interactions, and their effects on behavior, is one of psychological science's most important upcoming endeavors.

\section{FINAL COMMENTS}

It is useful to hypothesize ultimate explanations for phenomena already known to exist, and a strong metatheory needs to possess a set of principles and a logically rigorous conceptual framework to enable the derivation of theories to account for such phenomena. However, evolutionary hypothesis generation-like all hypothesis generation-is especially useful when it goes beyond offering a plausible account of known phenomena to also enable the deduction of additional, previously undiscovered psychological phenomena. These deductions-novel hypotheses about social-cognitive mechanisms operating at a proximate level of analysis - can then be tested and potentially falsified by empirical results.

What we have seen is that the evolutionary approach has been extremely successful along these lines. It has brought light to highly influential causal variables-for example, ovulation, disease vulnerability, facial symmetry, and ambient darkness-that lie outside the conceptual architectures of traditional social-cognitive theories. It has challenged implicit assumptions in social cognition that content matters less than process by revealing just how crucial content is if one wants to understand how people come to understand their social worlds, and it has uncovered subtle butcritical nuances in phenomena of great interest to social psychologists, ranging from the different emotional "flavors" of prejudices to the functionally specific ways in which people process information as a function of their currently active goals and vulnerabilities.

As ametatheory, the evolutionary approach has other strengths as well. It is integrative, linking phenomena to one another in coherent ways, as when the principle of differential parental investment can be used to explain social-cognitive phenomena ranging from mate preferences to the processing of status cues. It is also integrative in a broader, cross-disciplinary way, linking social psychology to cognitive science to anthropology to the biological sciences.
By rigorously applying the logical tools of evolutionary biology, we can not only gain a deeper appreciation for the ultimate origin of socialcognitive mechanisms but also more fully articulate how these proximate mechanisms operate in contemporary social circumstances.

\section{References}

Aarts, H., Dijksterhuis, A., \& De Vries, D. (2001). On the psychology of drinking: Being thirsty and perceptually ready. British Journal of Psychology, 92, 631-642. doi:10.1348/000712601162383

Abbey, A. (1982). Sex differences in attributions for friendly behavior: Do males misperceive females' friendliness? Journal of Personality and Social Psychology, 42, 830-838. doi:10.1037/00223514.42.5.830

Ackerman, J. M.,Becker, D. V., Mortensen, C. R., Sasaki, T., Neuberg S. L., \& Kenrick, D. T. (2009). A pox on the mind: Disjunction of attention and memory in the processing of physical disfigurement. Journal of Experimental Social Psychology, 45, 478-485. doji:10.1016/j.jesp.2008.12.008 erman, J. M., Shapiro, J. R., Neuberg, S. L., Kenrick, D. T., Schaller, M., Becker, D. V., . . Maner, J. K. (2006). They all look the same to me (unless they're angry): From out-group homogeneity to out-group heterogeneity. Psychological Science, 17, 836-840. doi:10.1111/j.1467-9280.2006.01790.x

Anderson, U. S., Perea, E. F., Becker, D. V., Ackerman, J. M., Shapiro, J. R., Neuberg, S. L., \& Kenrick, D. T. (2010). I only have eyes for you: Ovulation redirects attention (but not memory) to attractive men. Journal of Experimental Social Psychology, 46, 804-808. doi:10.1016/j.jesp.2010.04.015

Anthony, T., Copper, C., \& Mullen, B. (1992). Crossracial facial identification: A social cognitive integration. Personality and Social Psychology Bulletin, 18, 296-301. doi:10.1177/0146167292183005

Apicella, C. L., \& Marlowe, F. W. (2004). Perceived mate fidelity and paternal resemblance predict men's investment in children. Evolution and Human Behavior, 25, 371-378. doi:10.1016/j.evolhumbehav. 2004.06.003

Archer, J. (2006). Testosterone and human behavior: An evaluation of the challenge hypothesis. Neuroscience and Biobehavioral Reviews, 30, 319-345. doi:10.1016/j.neubiorev.2004.12.007

Balcetis, E., \& Dunning, D. (2010). Wishful seeing: More desired objects are seen as closer. Psychological Science, 21, 147-152. doi:10.1177/0956797609356283 
Bargh, J. A., Gollwitzer, P. M., \& Oettingen, G. (2010) Motivation. In S. T. Fiske, D. T. Gilbert, \& G. Lindzey (Eds.), Handbook of social psychology (5th ed., pp. 268-316). New York, NY: Wiley.

Bargh, J. A., \& Huang, J. Y. (2009). The selfish goal. In G. B. Moskowitz \& H. Grant (Eds.), The psychology of goals (pp. 127-150). New York, NY: Guilford Press.

Barrett, H. C., \& Kurzban, R. (2006). Modularity in cognition: Framing the debate. Psychological Review, 113, 628-647. doi:10.1037/0033-295X.113.3.628

Baumeister, R. F., \& Leary, M. R. (1995). The need to belong: Desire for interpersonal attachments as a fundamental human motivation. Psychological Bulletin, 117, 497-529. doi:10.1037/0033-2909.117.3.497

Becker, D. V., Anderson, U. S., Neuberg, S. L., Maner, J. K., Shapiro, J. R., Ackerman, J. M., . . Kenrick, D. T. (2010). More memory bang for the attentional buck: Self-protection goals enhance encoding efficiency for potentially threatening males. Social Psychological and Personality Science, 1, 182-189.

Becker, D. V., Kenrick, D. T., Guerin, S., \& Maner, J. K. (2005). Concentrating on beauty: Sexual selection and sociospatial memory. Personality and Social Psychology Bulletin, 31, 1643-1652. doi:10.1177/0146167205279583

Becker, D. V., Kenrick, D. T., Neuberg, S. L., Blackwell, K. C., \& Smith, D. M. (2007). The confounded nature of angry men and happy women. Journal of Personality and Social Psychology, 92, 179-190, doi:10.1037/0022-3514.92.2.179

Becker, D. V., Neel, R., \& Anderson, U. (2010). Ithusory conjunctions of angry facial expressions follow intergroup biases. Psychological Science, 21, 938-940. doi:10.1177/0956797610373374

Bernstein, M. J., Sacco, D. F., Brown, O. M., Young, S. G., \& Claypool, H. M. (2010). A preference for genuine smiles following social exclusion. Journal of Experimental Social Psychology, 46, 196-199. doi:10.1016/j.jesp.2009.08.010

Bernstein, M. J., Young, S. G., Brown, C. M., Sacco, D. F., \& Claypool, H. M. (2008). Adaptive responses to social exclusion: Social rejection improves detection of real and fake smiles. Psychological Science, 19, 981-983. doi:10.1111/j.1467-9280.2008.02187.x

Brewer, M. B. (2001). In-group identification and intergroup conflict: When does in-group love become out-group hate? In R. Ashmore, L. Jussim, \& D. Wilder (Eds.), Social identity, intergroup conflict, and conflict reduction (pp. 17-41). New York, NY: Oxford University Press.

Brewer, M. B., \& Caporael, L. (2006). An evolutionary perspective on social identity: Revisiting groups. In M. Schaller, J. A. Simpson, \& D. T. Kenrick (Eds.), Evolution and social psychology (pp. 143-161). New York, NY: Psychology Press.
Brown, C. M., Young, S. G., Sacco, D. F., Bernstein, M. J., \& Claypool, H. M. (2009). Social inclusion facilitates interest in mating. Evolutionary Psychology, 7, 11-27.

Brumbach, B. H., Figueredo, A. J., \& Ellis, B. J. (2009). Effects of harsh and unpredictable environments in adolescence on development of life history strategies. Human Nature, 20, 25-51. doi:10.1007/s12110-0099059-3

Bruner, J. S. (1957). On perceptual readiness. Psychological Review, 64, 123-152. doi:10.1037/ h0043805

Bruner, J. S., \& Goodman, C. C. (1947). Válue and need as organizing factors in perception. Journal of Abnormal and Social Psychology, 42, 33-44. doi:10.1037/h0058484

Buchner, A., Bell, R., Mehl, B., \& Musch, J. (2009). No enhanced recognition memory, but better source memory for faces of cheaters. Evolution and Human Behavior, 30, 212-224. doi:10.1016/j.evolhumbehav.2009.01.004

Bugental, D. B (2000). Acquisition of the algorithms of social life: Adomain-based approach. Psychological Bulletin, 126, 187-219. doi:10.1037/0033-2909. 126.2. 187

Burch, R. L., \& Gallup, G. G., Jr. (2000). Perceptions of paternal resemblance predict family violence. Evolution and Human Behavior, 21, 429-435. doi:10.1016/S1090-5138(00)00056-8

Burnstein, E. (2005). Altruism and genetic relatedness. In D. M. Buss (Ed.), The handbook of evolutionary psychology (pp. 528-551). Hoboken, NJ: Wiley.

Burnstein, E., Crandall, C., \& Kitayama, S. (1994). Some neo-Darwinian rules for altruism: Weighing cues for inclusive fitness as a function of the biological importance of the decision. Journal of Personality and Social Psychology, 67, 773-789. doi:10.1037/ 0022-3514.67.5.773

Buss, D. M. (1995). Evolutionary psychology: A new paradigm for social science. Psychological Inquiry, 6, 1-30. doi:10.1207/s15327965pli0601_1

Buss, D. M. (2004). Evolutionary psychology: The new science of the mind ( 2 nd ed.). Boston, MA: Pearson.

Buss, D. M., Larsen, R. J., Westen, D., \& Semmelroth, J. (1992). Sex differences in jealousy: Evolution, physiology, and psychology. Psychological Science, 3, 251-255. doi:10.1111/j.1467-9280.1992.tb00038.x

Buss, D. M., \& Schmitt, D. P. (1993). Sexual strategies theory: An evolutionary perspective on human mating. Psychological Review, 100, 204-232. doi:10.1037/0033-295X.100.2.204

Buss, D. M., \& Shackelford, T. K. (1997). From vigilance to violence: Mate retention tactics in married couples. Journal of Personality and Social Psychology, 72, 346-361. doi:10.1037/0022-3514.72.2.346 
Butz, D., \& Yogeeswaran, K. (2011). A new threat in the air: Macroeconomic threat increases prejudice against Asian Americans. Journal of Experimental Social Psychology, 47, 22-27. doi:10.1016/j. jesp.2010.07.014

Buunk, A. P., Park, J. H., \& Dubbs, S. L. (2008). Parentoffspring conflict in mate preferences. Review of General Psychology, 12, 47-62. doi:10.1037/ 1089-2680.12.1.47

Buunk, B. P., Angleitner, A., Obaid, V., \& Buss, D. M. (1996). Sex differences in jealousy in evolutionary and cultural perspective: Tests from the Netherlands, Germany, and the United States. Psychological Science, 7, 359-363. doi:10.1111/j.1467-9280.1996.tb00389.x

Byrne, D. (1961). Interpersonal attraction and attitude similarity. Journal of Abnormal and Social Psychology, 62, 713-715. doi:10.1037/h0044721

Campbell, A. (2005). Aggression. In D. M. Buss (Ed.), Handbook of evolutionary psychology (pp. 628-652). Hoboken, NJ: Wiley.

Campbell, D. T. (1982). Legal and primary-group social controls. Journal of Social and Biological Structures, 5, 431-438. doi:10.1016/S0140-1750(82)92071-1

Carney, D. R., Cuddy, A. J. C., \& Yap, A. J. (2010). Power posing: Brief nonverbal displays affect neuroendocrine levels and risk tolerance. Psychological Science, 21, 1363-1368. doi:10.1177/0956797610383437

Chagnon, N. A. (1988). Life histories, blood revenge, and warfare in a tribal population. Science, 239, 985-992 doi:10.1126/science.239.4843.985

Chance, J. E., \& Goldstein, A. G. (1996). The other-race effect and eyewitness identification. In S. L. Spører \& R. S. Malpass (Eds.), Psychological issuesin eyewitness identification (pp. 153-176). Hillsdale, NJ. Erlbaum.

Cohen-Bendahan, C. C. C., van de Beek, C., \& Berenbaum, S. A. (2005). Prenatal sex hormone effects on child and adult sex-typed behavior: Methods and findings. Neuroscience and Biobehavioral Reviews, 29, 353-384. doi:10.1016/j. neubiorev.2004.11.004

Conway, L. G., III, \& Schaller, M. (2002). On the verifiability of evofutionary psychological theories: An analysis of the psychology of scientific persuasion. Personality and Social Psychology Review, 6, 152-166. doi:10.1207/S15327957PSPR0602_04

Cook, M., \& Mineka, S. (1990). Selective associations in the observational conditioning of fear in rhesus monkeys. Journal of Experimental Psychology: Animal Behavior Processes, 16, 372-389. doi:10.1037/00977403.16.4.372

Cosmides, L. (1989). The logic of social exchange: Has natural selection shaped how humans reason? Studies with the Wason selection task. Cognition, 31, 187-276. doi:10.1016/0010-0277(89)90023-1
Cosmides, L., \& Tooby, J. (2005). Neurocognitive adaptations designed for social exchange. In D. M. Buss (Ed.), The handbook of evolutionary psychology (pp. 584-627). Hoboken, NJ: Wiley.

Cottrell, C. A., \& Neuberg, S. L. (2005). Different emotional reactions to different groups: A sociofunctional threat-based approach to "prejudice." Journal of Personality and Social Psychology, 88, 770-789. doi:10.1037/0022-3514.88.5.770

Daly, M., \& Wilson, M. (1988). Homicide. Hawthorne, NY: Aldine de Gruyter.

Daly, M., \& Wilson, M. (1998). The truth about Cinderella. London, England: Weidenfeld \& Nicolson.

Dawkins, R. (1976). The selfish gene. Oxford, England: Oxford University Press.

DeBruine, L., Jones, B. C., Frederick, D. A., Haselton, M. G., Penton-Voak, I. S., \&Perrett, D. I. (2010). Evidence for menstrual cycle shifts in women's preferences for masculinity: A response to Harris (in press) "Menstrual cycle and facial preferences reconsidered." Evolútionary Psychology, 8, 768-775.

DeBruine, L. M. (2005). Trustworthy but not lust-worthy: Context-specific effects of facial resemblance. Proceedings of the Royal Society B: Biological Sciences, 272.919-922. doi:10.1098/rspb.2004.3003

DeWall, C. N., \& Maner, J. K. (2008). High status men (but not women) capture the eye of the beholder. Evolutionary Psychology, 6, 328-341.

DeWall, C. N., Maner, J. K., \& Rouby, D. A. (2009). Social exclusion and early-stage interpersonal perception: Selective attention to signs of acceptance. Journal of Personality and Social Psychology, 96, 729-741. doi:10.1037/a0014634

Dobson, A. P., \& Carter, E. R. (1996). Infectious diseases and human population history. Bioscience, 46, 115-126. doi:10.2307/1312814

Downing, P. E., Jiang, Y., Shuman, M., \& Kanwisher, N. (2001). A cortical area selective for visual processing of the human body. Science, 293, 2470-2473. doi:10.1126/science.1063414

Dunbar, R. I. M. (2003). The social brain: Mind, language, and society in evolutionary perspective. Annual Review of Anthropology, 32, 163-181. doi:10.1146/annurev.anthro.32.061002.093158

Duncan, L. A., Park, J. H., Faulkner, J., Schaller, M., Neuberg, S. L., \& Kenrick, D. T. (2007). Adaptive allocation of attention: Effects of sex and sociosexuality on visual attention to attractive opposite-sex faces. Evolution and Human Behavior, 28, 359-364. doi:10.1016/j.evolhumbehav.2007.05.001

Duncan, L. A., \& Schaller, M. (2009). Prejudicial attitudes toward older adults may be exaggerated when people feel vulnerable to infectious disease: 
Evidence and implications. Analyses of Social Issues and Public Policy, 9, 97-115. doi:10.1111/j.15302415.2009.01188.x

Eibach, R. P., Libby, L. K., \& Ehrlinger, J. (2009). Priming family values: How being a parent affects moral evaluations of harmless but offensive acts. Journal of Experimental Social Psychology, 45, 1160 1163. doi:10.1016/j.jesp.2009.06.017

Eibach, R. P., \& Mock, S. E. (2011). The vigilant parent: Parental role salience affects parents' risk perceptions, risk-aversion, and trust in strangers. Journal of Experimental Social Psychology, 47, 694-697. doi:10.1016/j.jesp.2010.12.009

Eisenberger, N. I., Lieberman, M. D., \& Williams, K. D. (2003). Does rejection hurt? An fMRI study of social exclusion. Science, 302, 290-292. doi:10.1126/ science. 1089134

Ekman, P., \& Friesen, W. V. (1971). Constants across cultures in the face and emotion. Journal of Personality and Social Psychology, 17, 124-129. doi:10.1037/h0030377

Ekman, P., \& Friesen, W. V. (1975). Unmasking the face. Englewood Cliffs, NJ: Prentice-Hall.

Ellis, B. J., Figueredo, A. J., Brumbach, B. H., \& Schlomer, G. L. (2009). Fundamental dimensions of environmental risk. Human Nature, 20, 204-268. doi:10.1007/s12110-009-9063-7

Epstein, S., \& Levitt, H. (1962). The influence of hunger on the learning and recall of food related words. Journal of Abnormal and Social Psychology, 64, 130-135. doi:10.1037/h0040920

Ewald, P. W. (1994). Evolution of infectious disease. New York, NY: Oxford University Press.

Farris, C. A., Treat, T. A., Viken, R. J., McFall, R. M. (2008). Gender differences in perception of women's sexual intent. Psychological Science, 19, 348-354. doi:10.1111/j.1467-9280.2008.02092.x

Faulkner, J., \& Schaller, M (2007). Nepotistic nosiness: Inclusive fitness and vigilance of kin members' romantic retationships. Evolution and Human Behavior, 28, $430-438$. doi:10.1016/j.evolhumbehav.2007.06.001

Faulkner, J., Schaller, M., Park, J. H., \& Duncan, L. A. (2004). Evolved disease-avoidance mechanisms and contemporary xenophobic attitudes. Group Processes and Intergroup Relations, 7, 333-353. doi:10.1177/1368430204046142

Fessler, D. M. T., Eng, S. J., \& Navarrete, C. D. (2005). Elevated disgust sensitivity in the first trimester of pregnancy: Evidence supporting the compensatory prophylaxis hypothesis. Evolution and Human Behavior, 26, 344-351. doi:10.1016/j.evolhumbehav.2004.12.001

Figueredo, A. J., Vásquez, G., Brumbach, B. H., Schneider, S. M. R., Sefcek, J. A., Tal, I. R., ... . Jacobs, W. J. (2006). Consilience and life history theory: From genes to brain to reproductive strategy. Developmental Review, 26, 243-275. doi:10.1016/j. dr.2006.02.002

Figueredo, A. J., Vásquez, G., Brumbach, B. H., Sefcek, J. A., Kirsner, B. R., \& Jacobs, W. J. (2005). The K-factor: Individual differences in life history strategy. Personality and Individual Differences, 39, 1349-1360. doi:10.1016/j.paid.2005.06.009

Fincher, C. L., Thornhill, R., Murray, D. R., \& Schaller, M. (2008). Pathogen prevalence predicts human cross-cultural variability in individualism $K$. collectivism. Proceedings of the Royal Society B: Biological Sciences, 275, 1279-1285. đol:10.1098/ rspb.2008.0094

Flaxman, S. M., \& Sherman, P. Wø(2000). Morning sickness: A mechanism for protecting mother and embryo. Quarterly Review of Biology, 75, 113-148. doi:10.1086/393377

Gangestad, S. W., Haselton, M. G., \& Buss, D. M. (2006). Evolutionary foundations of cultural variation: Evoked culture and mate preferences. Psychological Inquiry, 17, 75-95. doi:10.1207/s15327965pli1702_1

Gangestad, S. W., \& Thornhill, R. (2008). Human oestrus. Proceedings of the Royal Society B: Biological Sciences, 275, 991-1000. doi:10.1098/rspb.2007.1425

Gangestad, S. W., Thornhill, R., \& Garver-Apgar (2005). Adaptations to ovulation. In D. M. Buss (Ed.), The handbook of evolutionary psychology (pp. 344-371). Hoboken, NJ: Wiley.

Geary, D. C. (2000). Evolution and the proximate expression of human paternal investment. Psychological Bulletin, 126, 55-77. doi:10.1037/00332909.126.1.55

Gibson, J. J. (1979). The ecological approach to visual perception. Boston, MA: Houghton Mifflin.

Gilchrist, J. C., \& Nesberg, L. S. (1952). Need and perceptual change in need-related objects. Journal of Experimental Psychology, 44, 369-376. doi:10.1037/ h0061823

Gonzaga, G. C., Haselton, M. G., Smurda, J., Davies, M. S., \& Poore, J. C. (2008). Love, desire, and the suppression of thoughts of romantic alternatives. Evolution and Human Behavior, 29, 119-125. doi:10.1016/j.evolhumbehav.2007.11.003

Gonzaga, G. C., Keltner, D., Londahl, E. A., \& Smith, M. D. (2001). Love and the commitment problem in romantic relations and friendship. Journal of Personality and Social Psychology, 81, 247-262. doi:10.1037/0022-3514.81.2.247

Gray, P. B., Kahlenberg, S. M., Barrett, E. B., Lipson, S. F., \& Ellison, P. T. (2002). Marriage and fatherhood are associated with lower testosterone in males. Evolution and Human Behavior, 23, 193-201. doi:10.1016/S1090-5138(01)00101-5 
Grillon, C., Pellowski, M., Merikangas, K. R., \& Davis, M. (1997). Darkness facilitates acoustic startle reflex in humans. Biological Psychiatry, 42, 453-460. doi:10.1016/S0006-3223(96)00466-0

Griskevicius, V., Ackerman, J. A., Cantu, S. M., Delton, A. W., Robertson, T. E., Simpson, J. A., . . Tybur, J. M. (2013). When the economy falters do people spend or save? Responses to resource scarcity depend on childhood environments. Psychological Science, 24, 197-205.

Griskevicius, V., Delton, A. W., Robertson, T. E., \& Tybur, J. M. (2011). Environmental contingency in life history strategies: The influence of mortality and socioeconomic status on reproductive timing. Journal of Personality and Social Psychology, 100, 241-254. doi:10.1037/a0021082

Griskevicius, V., Tybur, J. M., Delton, A. W., \& Robertson, T. E. (2011). The influence of mortality and socioeconomic status on risk and delayed rewards: A life history theory approach. Journal of Personality and Social Psychology, 100, 1015-1026. doi:10.1037/a0022403

Haas, J. (1990). The anthropology of war. New York, NY: Cambridge University Press.

Hahn-Holbrook, J., Holbrook, C., \& Haselton, M. (2011) Parental precaution: Adaptive ends and neurobiological means. Neuroscience and Biobehavioral Reviews, 35, 1052-1066. doi:10.1016/j.neubiorev.2010.09.015

Hamilton, W. D. (1964a). The genetical evolution of social behaviour I. Journal of Theoretical Biology, 7 , 1-16. doi:10.1016/0022-5193(64)90038-4

Hamilton, W. D. (1964b). The genetical evolution of social behaviour II. Journal of Theoretical Biology, 7 , $17-52$.

Harris, P. L., Núñez, M., \& Brett, C. (2001). Eet's swap: Early understanding of social exchange by British and Nepali children. Memory and Oognition, 29, $757-$ 764. doi:10.3758/BF03200478

Haselton, M., \& Miller, G. F. (2006). Women's fertility across the cycle increases the short-term attractiveness of creative intelligence. Human Nature, 17, 50-73. doi:10.1007/s12110-006-1020-0

Haselton, M. G., \& Buss, D. M. (2000). Error management theory: A new perspective on biases in cross-sex mind reading. Journal of Personality and Social Psychology, 78, 81-91. doi:10.1037/00223514.78.1.81

Haselton, M. G., \& Gangestad, S. W. (2006). Conditional expression of women's desires and men's mateguarding across the ovulatory cycle. Hormones and Behavior, 49, 509-518. doi:10.1016/j. yhbeh.2005.10.006

Haselton, M. G., \& Gildersleeve, K. (2011). Can men detect ovulation? Current Directions in Psychological Science, 20, 87-92. doi:10.1177/0963721411402668
Haselton, M. G., \& Nettle, D. (2006). The paranoid optimist: An integrative evolutionary model of cognitive biases. Personality and Social Psychology Review, 10, 47-66. doi:10.1207/ s15327957pspr1001_3

Henningsen, D. D., Henningsen, M. L. M., \& Valde, K. (2006). Gender differences in perceptions of women's sexual interest during cross-sex interactions: An application and extension of cognitive valence theory. Sex Roles, 54, 821-829. doi:10.1007/s11199006-9050-y

Henrich, J., \& Boyd, R. (1998). The evolution of conformist transmission and between-group differences. Evolution and Human Behavior, 19, 215-241. doi:10.1016/S1090-5138(98)00018-X

Henrich, J., \& Gil-White, F. J. (2001). The evolution of prestige: Freely conferred deference as a mechanism for enhancing the benefits of cultural transmission. Evolution and Human Behavior, 22, 165-196. doi:10.1016/S1090-5138(00)00071-4

Hill, K., \& Kaplan, H. (1999). Life history traits in humans: Theory and empirical studies. Annual Review of Anthropology, 28, 397-430. doi:10.1146/ annurev.anthro.28.1.397

Hill, S.E. \& Buss, D. M. (2008). The evolutionary psyChology of envy. In R. H. Smith (Ed.), Envy: Theory and research (pp. 60-70). New York, NY: Oxford University Press.

Hill, S. E., DelPriore, D. J., \& Vaughan, P. W. (2011). The cognitive consequences of envy: Attention, memory, and self-regulatory depletion. Journal of Personality and Social Psychology, 101, 653-666. doi:10.1037/ a0023904

Hill, S. E., Rodeheffer, C., Griskevicius, V., Durante, K. M., \& White, A. E. (2012). Boosting beauty in an economic decline: Mating, spending, and the lipstick effect. Journal of Personality and Social Psychology, 103, 275-291. doi:10.1037/a0028657

Hrdy, S. B. (1999). Mother nature: A history of mothers, infants, and natural selection. New York, NY: Pantheon.

Huang, J., Sedlovskaya, A., Ackerman, J., \& Bargh, J. (2011). Immunizing against prejudice: Effects of disease protection on attitudes toward out groups. Psychological Science, 22, 1550-1556. doi:10.1177/0956797611417261

Johnston, L., Arden, K., Macrae, C. N., \& Grace, R. C. (2003). The need for speed: The menstrual cycle and person construal. Social Cognition, 21, 89-100. doi:10.1521/soco.21.2.89.21319

Jones, B. C., DeBruine, L. M., Perrett, D. I., Little, A. C., Feinberg, D. R., \& Law Smith, M. J. (2008). Effects of menstrual cycle phase on face preferences. Archives of Sexual Behavior, 37, 78-84. doi:10.1007/ s10508-007-9268-y 
Jones, J. T., Pelham, B. W., Carvallo, M., \& Mirenberg, M. C. (2004). How do I love thee? Let me count the Js: Implicit egotism and interpersonal attraction. Journal of Personality and Social Psychology, 87, 665-683. doi:10.1037/0022-3514.87.5.665

Kahneman, D., \& Tversky, A. (1979). Prospect theory: An analysis of decision under risk. Econometrica, 47, 263-291. doi:10.2307/1914185

Kanwisher, N., McDermott, J., \& Chun, M. M. (1997). The fusiform face area: A module in human extrastriate cortex specialized for face perception. Journal of Neuroscience, 17, 4302-4311.

Kaplan, H. S., \& Gangestad, S. W. (2005). Life history theory and evolutionary psychology. In D. M. Buss (Ed.), The handbook of evolutionary psychology (pp. 68-95). Hoboken, NJ: Wiley.

Keegan, J. (1993). A history of warfare. New York, NY: Knopf.

Keeley, L. H. (1996). War before civilization: The myth of the peaceful savage. New York, NY: Oxford University Press.

Kelly, R. C. (2005). The evolution of lethal intergroup violence. Proceedings of the National Academy of Sciences, USA, 102, 15294-15298. doi:10.1073/ pnas. 0505955102

Kenrick, D. T., Delton, A. W., Robertson, T., Becker, D. V., \& Neuberg, S. L. (2007). How the mind warps: A social evolutionary perspective on cognitive pro cessing disjunctions. In J. P. Forgas, M. G. Haselton, $\&$ W. Von Hippel (Eds.), The evolution of the social mind: Evolution and social cognition (pp. 49-68). New York, NY: Psychology Press.

Kenrick, D. T., Griskevicius, V., Neuberg, S. L., \& Schaller, M. (2010). Renovating the pyramid of needs: Contemporary extensions built upon ancient foundations. Perspectives on Psychological Science, 5, 292-314. doi:10.1177/1745691610369469

Kenrick, D. T., Griskevicius, V., Sundie, J. M., Li, N. P., Li, Y. J., \& Neuberg, S.L. (2009). Deep rationality: The evolutionary economics of decision-making. Social Cognition, 27, 764-785. doi:10.1521/soco.2009.27.5.764

Kenrick, D. \& Keefe, R. C. (1992). Age preferences in mates reflect sex differences in mating strategies Béhavioral and Brain Sciences, 15, 75-91. doi. $10.1017 /$ S0140525X00067595

Kenrick, D. T., Li, N. P., \& Butner, J. (2003). Dynamical evolutionary psychology: Individual decision rules and emergent social norms. Psychological Review, 110, 3-28. doi:10.1037/0033-295X.110.1.3

Kenrick, D. T., \& Luce, C. L. (2000). An evolutionary life-history model of gender differences and similarities. In T. Eckes \& H. M. Trautner (Eds.), The developmental social psychology of gender (pp. 35-64). Hillsdale, NJ: Erlbaum.
Kenrick, D. T., Neuberg, S. L., Griskevicius, V., Becker, D. V., \& Schaller, M. (2010). Goal-driven cognition and functional behavior: The fundamental motives framework. Current Directions in Psychological Science, 19, 63-67. doi:10.1177/0963721409359281

Kenrick, D. T., Neuberg, S. L., Zierk, K. L., \& Krones, J. M. (1994). Evolution and social cognition: Contrast effects as a function of sex, dominance, and physical attractiveness. Personality and Social Psychology Bulletin, 20, 210-217. doi:10.1177/0146167294202008

Ketelaar, T., \& Ellis, B. J. (2000). Are evolutionary explanations unfalsifiable? Evolutionary psychology and the Lakatosian philosophy of science. Psychological Inquiry, 11, 1-21. doi:10.1207/SI5327965PLI1101_01

Kostic, B., McFarlan, C. C., \& Cleary, A. M. (2012). Extensions of the surviyal advantage in memory: Examining the role of ancestral context and implied social isolation. Journat of Experimental Psychology: Learning, Memory and Cognition, 38, 1091-1098. doi:10.1037/a0026974

Kunstman, J W., \& Maner, J. K. (2011). Sexual overperception: Power, mating goals, and biases in socialjudgment. Journal of Personality and Social Psychology, 100, 282-294. doi:10.1037/a0021135

Kurland, J. A., \& Gaulin, S. (2005). Cooperation and conflict among kin. In D. M. Buss (Ed.), Handbook of evolutionary psychology (pp. 447-482). New York, NY: Wiley.

Kurzban, R., \& Leary, M. R. (2001). Evolutionary origins of stigmatization: The functions of social exclusion. Psychological Bulletin, 127, 187-208. doi:10.1037/0033-2909.127.2.187

Kurzban, R., Tooby, J., \& Cosmides, L. (2001). Can race be erased? Coalitional computation and social categorization. Proceedings of the National Academy of Sciences, USA, 98, 15387-15392. doi:10.1073/ pnas. 251541498

Laham, S. M., Gonsalkorale, K., \& von Hippel, W. (2005). Darwinian grandparenting: Preferential investment in more certain kin. Personality and Social Psychology Bulletin, 31, 63-72. doi:10.1177/0146167204271318

Leakey, R. E., \& Lewin, R. (1977). Origins: What new discoveries reveal about the emergence of our species and its possible future. New York, NY: Dutton.

Li, N. P., Bailey, J. M., Kenrick, D. T., \& Linsenmeier, J. A. (2002). The necessities and luxuries of mate preferences: Testing the tradeoffs. Journal of Personality and Social Psychology, 82, 947-955. doi:10.1037/0022-3514.82.6.947

Li, N. P., \& Kenrick, D. T. (2006). Sex similarities and differences in preferences for short-term mates: What, whether, and why. Journal of Personality and Social Psychology, 90, 468-489. doi:10.1037/00223514.90.3.468 
Li, Y. J., Kenrick, D. T., Griskevicius, V., \& Neuberg, S. L. (2012). Economic decision biases and fundamental motivations: How mating and self-protection alter loss aversion. Journal of Personality and Social Psychology, 102, 550-561. doi:10.1037/a0025844

Lieberman, D., Tooby, J., \& Cosmides, L. (2007). The architecture of human kin detection. Nature, 445, 727-731. doi:10.1038/nature05510

Little, A. C., DeBruine, L. M., \& Jones, B. C. (2011) Exposure to visual cues of pathogen contagion changes preferences for masculinity and symmetry in opposite-sex faces. Proceedings of the Royal Academy B: Biological Sciences, 278, 2032-2039. doi:10.1098/ rspb.2010.1925

MacDonald, G., \& Leary, M. R. (2005). Why does social exclusion hurt? The relationship between social and physical pain. Psychological Bulletin, 131, 202-223. doi:10.1037/0033-2909.131.2.202

Macrae, C. N., Alnwick, K. A., Milne, A. B., \& Schloerscheidt, A. M. (2002). Person perception across the menstrual cycle: Hormonal influences on social-cognitive functioning. Psychological Science, 13, 532-536. doi:10.1111/1467-9280.00493

Maner, J. K., DeWall, C. N., Baumeister, R. F., \& Schaller, M. (2007). Does social exclusion motivate withdrawal or reconnection? Resolving the "porcupine problem." Journal of Personality and Social Psychology, 92, 42-55. doi:10.1037/00223514.92.1.42

Maner, J. K., DeWall, C. N., \& Gailliot, M. T. (2008). Selective attention to signs of success: Social dominance and early stage interpersonal perception. Personality and Social Psychology Bulletin, 34 488-501. doi:10.1177/0146167207311910

Maner, J. K., Gailliot, M. T., \& DeWall, C.N. (2007). Adaptive attentional attunement: Evidence for mating-related perceptual bias. Evolution and Human Behavior, 28, 28-36. doi:10.1016/j.evolhumbehav. 2006.05.006

Maner, J. K., Gailliot, M A \& Miller, S. L. (2009). The implicit cognition of relationship maintenance: Inattention to attractive alternatives. Journal of Experimental) Social Psychology, 45, 174-179. doi:10.1016/j.jesp.2008.08.002

Maner, J. K., Gailliot, M. T., Rouby, D. A., \& Miller, S. L. (2007). Can't take my eyes off you: Attentional adhesion to mates and rivals. Journal of Personality and Sócial Psychology, 93, 389-401. doi:10.1037/ 0022-3514.93.3.389

Maner, J. K., Kenrick, D. T., Becker, D. V., Delton, A. W., Hofer, B., Wilbur, C. J., \& Neuberg, S. L. (2003). Sexually selective cognition: Beauty captures the mind of the beholder. Journal of Personality and Social Psychology, 85, 1107-1120. doi:10.1037/ 0022-3514.85.6.1107
Maner, J. K., Kenrick, D. T., Becker, D. V., Robertson, T., Hofer, B., Delton, A. W., . . S Schaller, M. (2005). Functional projection: How fundamental social motives can bias interpersonal perception. Journal of Personality and Social Psychology, 88, 63-78. doi:10.1037/0022-3514.88.1.63

Maner, J. K., Miller, S. L., Moss, J. H., Leo, J. L., \& Plant, E. A. (2012). Motivated social categorization: Fundamental motives enhance people's sensitivity to basic social categories. Journal of Personality and Social Psychology, 103, 70-83. doi:10.1037/a0028172

Maner, J. K., Miller, S. L., Rouby, D. A., \& Gailliot.M. T. (2009). Intrasexual vigilance: The implicit cognition of romantic rivalry. Journal of Personality and Social Psychology, 97, 74-87. doi:10.1037//a0014055

Maner, J. K., Miller, S. L., Schmidt, N. B., \& Eckel, L. A. (2010). The endocrinology of exclusion: Rejection elicits motivationally tuned changes in progesterone. Psychological Science, 21, 581-588 doi:10.1177/0956797610362676

Maner, J. K., Rouby, D. A., \& Gonzaga, G. (2008). Automatic inattention to attractive alternatives: The evolved psychology of relationship maintenance. Evolution and Human Behavior, 29, 343-349. doi:10.1016/j.evolhumbehav.2008.04.003

Mascaro,O., \& Csibra, G. (2012). Representation of stable social dominance relations by human infants. Proceedings of the National Academy of Sciences, USA, 109, 6862-6867. doi:10.1073/pnas.1113194109

Maslow, A. H. (1943). A theory of human motivation. Psychological Review, 50, 370-396. doi:10.1037/ h0054346

Mayr, E. (1976). Evolution and the diversity of life. Cambridge, MA: Harvard University Press.

Mazur, A., \& Booth, A. (1998). Testosterone and dominance in men. Behavioral and Brain Sciences, 21, 353-363. doi:10.1017/S0140525X98001228

McArthur, L. Z., \& Baron, R. M. (1983). Toward an ecological theory of social perception. Psychological Review, 90, 215-238. doi:10.1037/0033295X.90.3.215

Michalski, R. L., \& Shackelford, T. K. (2005). Grandparental investment as a function of relational uncertainty and emotional closeness with parents. Human Nature, 16, 293-305. doi:10.1007/s12110-005-1012-5

Miller, G. (2007). Reconciling evolutionary psychology and ecological psychology: How to perceive fitness affordances. Acta Psychologica Sinica, 39, 546-555.

Miller, G. F., \& Todd, P. M. (1998). Mate choice turns cognitive. Trends in Cognitive Sciences, 2, 190-198. doi:10.1016/S1364-6613(98)01169-3

Miller, S. L., \& Maner, J. K. (2010a). Evolution and relationship maintenance: Fertility cues lead committed men to devalue relationship alternatives. Journal 
of Experimental Social Psychology, 46, 1081-1084. doi:10.1016/j.jesp.2010.07.004

Miller, S. L., \& Maner, J. K. (2010b). Scent of a woman: Male testosterone responses to female olfactory ovulation cues. Psychological Science, 21, 276-283. doi:10.1177/0956797609357733

Miller, S. L., \& Maner, J. K. (2011a). Ovulation as a mating prime: Subtle signs of female fertility influence men's mating cognition and behavior. Journal of Personality and Social Psychology, 100, 295-308. doi:10.1037/a0020930

Miller, S. L., \& Maner, J. K. (2011b). Sick body, vigilant mind: The biological immune system activates the behavioral immune system. Psychological Science, 22, 1467-1471. doi:10.1177/0956797611420166

Miller, S. L., \& Maner, J. K. (2012). Overperceiving disease cues: The basic cognition of the behavioral immune system. Journal of Personality and Social Psychology, 102, 1198-1213. doi:10.1037/a0027198

Miller, S. L., Maner, J. K., \& Becker, D. V. (2010). Selfprotective biases in group categorization: Threat cues shape the psychological boundary between "us" and "them." Journal of Personality and Social Psychology, 99, 62-77. doi:10.1037/a0018086

Møller, A. P., \& Thornhill, R. (1998). Bilateral symmetry and sexual selection: A meta-analysis. American Naturalist, 151, 174-192. doi:10.1086/286110

Moore, B. R. (2004). The evolution of learning. Biological Reviews of the Cambridge Philosophical Society, 79 301-335. doi:10.1017/S1464793103006225

Mortensen, C. R., Becker, D. V., Ackerman, J.M. Neuberg, S. L., \& Kenrick, D. T. (2010)-Infection breeds reticence: The effects of disease sálience on self-perceptions of personality and behavioral avoidance tendencies. Psychologicak Science, 21, 440-447. doi:10.1177/0956797610361706

Mumme, D. L., \& Fernald, A. (2003). The infant as onlooker: Learning from emotional reactions observed ina television scenario. Child Development, 74, 221-237. doi:10.1111/14678624.00532

Murray, D. R., Trudeau, R., \& Schaller, M. (2011). On the origins of cross-cultural differences in conformity: Four tests of the pathogen prevalence hypothesis. Personality and Social Psychology Bulletin, 37, 318-329. doi:10.1177/0146167210394451

Nairne, J. S., \& Pandeirada, J. N. S. (2008). Adaptive memory: Remembering with a stone-age brain. Current Directions in Psychological Science, 17, 239-243. doi:10.1111/j.1467-8721.2008.00582.x

Nairne, J. S., \& Pandeirada, J. N. S. (2010). Adaptive memory: Ancestral priorities and the mnemonic value of survival processing. Cognitive Psychology, 61, 1-22. doi:10.1016/j.cogpsych.2010.01.005
Navarrete, C. D., \& Fessler, D. M. T. (2006). Disease avoidance and ethnocentrism: The effects of disease vulnerability and disgust sensitivity on intergroup attitudes. Evolution and Human Behavior, 27, 270-282. doi:10.1016/j.evolhumbehav.2005.12.001

Navarrete, C. D., Fessler, D. M. T., \& Eng, S. J. (2007). Elevated ethnocentrism in the first trimester of pregnancy. Evolution and Human Behavior, 28, 60-65. doi:10.1016/j.evolhumbehav.2006.06.002

Navarrete, C. D., McDonald, M. M., Molina, L. E. \& Sidanius, J. (2010). Prejudice at the nexus of race and gender: An out-group male target hypothesis. Journal of Personality and Social Psychology, 98, 933-945. doi:10.1037/a0017931

Navarrete, C. D., Olsson, A., Ho, A. K, Mendes, W. B., Thomsen, L., \& Sidanius, J. (2009). Fear extinction to an out-group face: The role of target gender. Psychological Science, 20, 155-158. doi:10.1111/ j.1467-9280.2009.02273.x

Neel, R., Becker, D. V.. Neuberg, S. L., \& Kenrick, D. T. (2012) Who expressed what emotion? Men grab anger, women grab happiness. Journal of Experimental Social Psychology, 48, 583-586. dox:10,1016/j.jesp.2011.11.009

Nesse, R. M. (2005). Natural selection and the regulation of defenses: A signal detection analysis of the smoke detector principle. Evolution and Human Behavior, 26, 88-105. doi:10.1016/j.evolhumbehav.2004.08.002

Neuberg, S. L., Becker, D. V., \& Kenrick, D. T. (2013) Evolutionary social cognition. In D. E. Carlston (Ed.), Oxford handbook of social cognition (pp. 656-679). New York, NY: Oxford University Press.

Neuberg, S. L., Kenrick, D. T., \& Schaller, M. (2010). Evolutionary social psychology. In S. T. Fiske, D. Gilbert, \& G. Lindzey (Eds.), Handbook of social psychology (pp. 761-796). New York, NY: Wiley.

Neuberg, S. L., Kenrick, D. T., \& Schaller, M. (2011). Human threat management systems: Selfprotection and disease avoidance. Neuroscience and Biobehavioral Reviews, 35, 1042-1051. doi:10.1016/j. neubiorev.2010.08.011

New, J., Cosmides, L., \& Tooby, J. (2007). Categoryspecific attention for animals reflects ancestral priorities, not expertise. Proceedings of the National Academy of Sciences, USA, 104, 16598-16603. doi:10.1073/pnas.0703913104

Norenzayan, A., Schaller, M., \& Heine, S. J. (2006). Evolution and culture. In M. Schaller, J. A. Simpson, \& D. T. Kenrick (Eds.), Evolution and social psychology (pp. 343-366). New York, NY: Psychology Press.

Norenzayan, A., Schaller, S., \& Heine, S. J. (2010). Introduction. In M. Schaller, A. Norenzayan, S. J. Heine, T. Yamagishi, \& T. Kameda (Eds.), Evolution, culture, and the human mind (pp. 1-5). New York, NY: Psychology Press/Taylor \& Francis. 
Oaten, M., Stevenson, R. J., \& Case, T. I. (2011). Disease avoidance as a functional basis for stigmatization. Philosophical Transactions of the Royal Society of London Series B: Biological Sciences, 366, 3433-3452. doi:10.1098/rstb.2011.0095

Öhman, A., Flykt, A., \& Esteves, F. (2001). Emotion drives attention: Detecting the snake in the grass. Journal of Experimental Psychology: General, 130, 466-478. doi:10.1037/0096-3445.130.3.466

Öhman, A., \& Mineka, S. (2001). Fears, phobias, and preparedness: Toward an evolved module of fear and fear learning. Psychological Review, 108, 483-522. doi:10.1037/0033-295X.108.3.483

Olsson, A., Ebert, J. P., Banaji, M. R., \& Phelps, E. A. (2005). The role of social groups in the persistence of learned fear. Science, 309, 785-787. doi:10.1126/ science.1113551

Park, J., Schaller, M., \& Van Vugt, M. (2008). The psychology of human kin recognition: Heuristic cues, erroneous inferences, and their implications. Review of General Psychology, 12, 215-235. doi:10.1037/1089-2680.12.3.215

Park, J. H., Faulkner, J., \& Schaller, M. (2003). Evolved disease-avoidance processes and contemporary anti-social behavior: Prejudicial attitudes and avoidance of people with physical disabilities. Journal of Nonverbal Behavior, 27, 65-87. doi:10.1023/A:1023910408854

Park, J. H., \& Schaller, M. (2005). Does attitude similarity serve as a heuristic cue for kinship? Evidence of an implicit cognitive association. Evolution and Human Behavior, 26, 158-170. doi:10.1016/j.evolhumbehav. 2004.08.013

Park, J. H., Schaller, M., \& Crandall, C. S. (2007). Pathogen-avoidance mechanisms and the stigmatization of obese people. Evolution and Human Behavior, 28, 410-414. doi:10,1016/j.evolhumbehav.2007.05.008

Penton-Voak, I. S., \& Perrett, D. 1. (2000). Female preference for male faces changes cyclically: Further evidence. Evolution and Human Behavior, 21, 39-48. doi:10.1016/S1090-5138(99)00033-1

Perilloux, C., Eastôn, J. A., \& Buss, D. M. (2012). The misperception of sexual interest. Psychological Science, 23, 146-151. dori:10.1177/0956797611424162

Perilloux, C., Fleischman, D. S., \& Buss, D. M. (2008).

The daughter guarding hypothesis: Parental influence on, and emotional reactions to, offspring's mating behavior. Evolutionary Psychology, 6, 217-233.

Pickett, C. L., Gardner, W. L., \& Knowles, M. (2004). Getting a cue: The need to belong and enhanced sensitivity to social cues. Personality and Social Psychology Bulletin, 30, 1095-1107. doi:10.1177/0146167203262085
Pietrzak, R. H., Laird, J. D., Stevens, D. A., \& Thompson, N. S. (2002). Sex differences in human jealousy: A coordinated study of forced-choice, continuous rating-scale, and physiological responses on the same subjects. Evolution and Human Behavior, 23, 83-94. doi:10.1016/S1090-5138(01)00078-2

Pinker, S. (2003). The blank slate. New York, NY: Penguin.

Pinker, S. (2011). The better angels of our nature. New York, NY: Viking.

Plant, E. A., Goplen, J., \& Kunstman, J. W. (2011). Selective responses to threat: The roles of race and gender in decisions to shoot. Personality and Social Psychology Bulletin, 37, 1274-1281. doi:10.1177/0146167211408617

Platek, S. M., Raines, D. M., Gallup, G. G., Jr., Mohamed, F. B., Thomson, J. W., Myers, I. E., . . Arigo, D. R. (2004). Reactions to children's faces: Males are more affected by resemblance than females are, and so are their brains. Evolution and Human Behavior, 25, 394-405. doi:10.1016/j.evolhumbehav.2004.08.007

Pollet, T. V., Nettle, D., \& Nelissen, M. (2007). Maternal grandmothers do go the extra mile: Factoring distance and lineage into differential contact with grandchildren. Evolutionary Psychology, 5, 832-843.

Pratto, F., Sidanius, J., Stallworth, L. M., \& Malle, B. F (1994). Social dominance orientation: A personality variable predicting social and political attitudes. Journal of Personality and Social Psychology, 67, 741-763. doi:10.1037/0022-3514.67.4.741

Radel, R., \& Clément-Guillotin, C. (2012). Evidence of motivational influences in early visual perceptions: Hunger modulates conscious access. Psychological Science, 23, 232-234. doi:10.1177/0956797611427920

Ratcliff, N. J., Bernstein, M. J., Cundiff, J. L., \& Vescio, T. K. (2012). Seeing wrath from the top (through stratified lenses): Perceivers high in social dominance orientation show superior anger identification for high-status individuals. Journal of Experimental Social Psychology, 48, 1373-1376.

Ratcliff, N. J., Hugenberg, K., Shriver, E., \& Bernstein, M. J. (2011). The allure of power: The effect of status on face memory. Personality and Social Psychology Bulletin, 37, 1003-1015. doi:10.1177/0146167211407210

Reid, S. A., Zhang, J., Anderson, G. A., Gasiorek, J., Bonilla, D., \& Peinado, S. (2012). Parasite primes make foreign-accented English sound more distant to people who are disgusted by pathogens (but not by sex or morality). Evolution and Human Behavior, 33, 471-478. doi:10.1016/j.evolhumbehav.2011.12.009

Richerson, P., \& Boyd, R. (1995, January). The evolution of human hypersociality. Paper for Ringberg Castle Symposium on Ideology, Warfare and Indoctrinability. 
Roney, J. R., Lukaszewski, A. W., \& Simmons, Z. L. (2007). Rapid endocrine responses of young men to social interactions with young women. Hormones and Behavior, 52, 326-333. doi:10.1016/j. yhbeh.2007.05.008

Rule, N. O., Rosen, K. S., Slepian, M. L., \& Ambady, N. (2011). Mating interest improves women's accuracy in judging male sexual orientation. Psychological Science, 22, 881-886. doi:10.1177/0956797611412394

Sadalla, E. K., Kenrick, D. T., \& Vershure, B. (1987). Dominance and heterosexual attraction. Journal of Personality and Social Psychology, 52, 730-738. doi:10.1037/0022-3514.52.4.730

Sagarin, B. J. (2005). Reconsidering evolved sex differences in jealousy: Comment on Harris (2003). Personality and Social Psychology Review, 9, 62-75. doi:10.1207/s15327957pspr0901_5

Sagarin, B. J., Becker, D. V., Guadagno, R. E., Nicastle, L. D., \& Millevoi, A. (2003). Sex differences (and similarities) in jealousy: The moderating influence of infidelity experience and sexual orientation of the infidelity. Evolution and Human Behavior, 24, 17-23. doi:10.1016/S1090-5138(02)00106-X

Salmon, C. (2005). Parental investment and parentoffspring conflict. In D. M. Buss (Ed.), The handbook of evolutionary psychology (pp. 506-527). Hoboken, NJ: Wiley.

Schaller, M. (2011). The behavioural immune system and the psychology of human sociality. Philosophical Transactions of the Royal Society of London Series B: Biological Sciences, 366, 3418-3426. doi:10.1098/ rstb.2011.0029

Schaller, M., \& Abeysinghe, A. M. N. D.(2006) Geographical frame of reference and dangerous intergroup attitudes: A double-minority study in Sri Lanka. Political Psychology, 27, 615-631. doi:10.1111/j.1467-9221.2006.00521.x

Schaller, M., \& Duncan, R.A. (2007). The behavioral immune system:-1ts evolution and social psychological implications. Iny. P. Forgas, M. G. Haselton, \& W. von Hippet (Eds.), Evolution and the social mind: Evolutionary psychology and social cognition (pp. 293-307). New York, NY: Psychology Press.

Schallen, M., \& Murray, D. R. (2008). Pathogens, personality and culture: Disease prevalence predicts worldwide variability in sociosexuality, extraversion, and openness to experience. Journal of Personality and Social Psychology, 95, 212-221. doi:10.1037/00223514.95.1.212

Schaller, M., \& Murray, D. R. (2011). Infectious disease and the creation of culture. In M. Gelfand, C.-Y. Chiu, \& Y.-Y. Hong (Eds.), Advances in culture and psychology (Vol. 1, pp. 99-151). New York, NY: Oxford University Press.
Schaller, M., \& Neuberg, S. L. (2008). Intergroup prejudices and intergroup conflicts. In C. Crawford \& D. L. Krebs (Eds.), Foundations of evolutionary psychology: Ideas, applications, and applications (pp. 401-414). Mahwah, NJ: Erlbaum.

Schaller, M., \& Neuberg, S. L. (2012). Danger, disease, and the nature of prejudice(s). Advances in Experimental Social Psychology, 46, 1-55. doi:10.1016/B978-0-12394281-4.00001-5

Schaller, M., Neuberg, S. L., Griskevicius, V., $\&$ Kenrick, D. T. (2010). Pyramid power. Perspectives on Psychological Science, 5, 335-337. doi:10.1177/1745691610369474

Schaller, M., \& Park, J. H. (2011). Thebehavioral immune system (and why it matters). Current Directions in Psychological Science, 20, 99-103. doi:10.1177/0963721411402596

Schaller, M., Park, J. H. \& Faulkner, J. (2003). Prehistoric dangers and contemporary prejudices. European Review of 'Social Psychology, 14, 105-137. doi:10.1080/10463280340000036

Schaller, M.Park, J. H., \& Mueller, A. (2003). Fear of the dark. Interactive effects of beliefs about danger and ambient darkness on ethnic stereotypes. Personality and Social Psychology Bulletin, 29, 637-649. doi:10.1177/0146167203029005008

Schmitt, D. P., \& Pilcher, J. J. (2004). Evaluating evidence of psychological adaptation: How do we know one when we see one? Psychological Science, 15, 643649. doi:10.1111/j.0956-7976.2004.00734.x

Shackelford, T. K., LeBlanc, G. J., \& Drass, E. (2000). Emotional reactions to infidelity. Cognition and Emotion, 14, 643-659. doi:10.1080/02699930050117657

Sherman, G. D., Haidt, J., \& Coan, J. A. (2009). Viewing cute images increases behavioral carefulness. Emotion, 9, 282-286. doi:10.1037/a0014904

Shidlovski, D., \& Hassin, R. R. (2011). When pooping babies become more appealing: The effects of nonconscious goal pursuit on experienced emotions. Psychological Science, 22, 1381-1385. doi:10.1177/0956797611417135

Sidanius, J., \& Pratto, F. (1999). Social dominance: An intergroup theory of social hierarchy and oppression. New York, NY: Cambridge University Press. doi:10.1017/CBO9781139175043

Sidanius, J., \& Veniegas, R. C. (2000). Gender and race discrimination: The interactive nature of disadvantage. In S. Oskamp (Ed.), Reducing prejudice and discrimination (pp. 47-69). Mahwah, NJ: Erlbaum.

Simpson, J. A., Gangestad, S. W., \& Lerma, M. (1990). Perception of physical attractiveness: Mechanisms involved in the maintenance of romantic relationships. Journal of Personality and Social Psychology, 59, 1192-1201. doi:10.1037/0022-3514.59.6.1192 
Simpson, J. A., Griskevicius, V., Kuo, S. I., Sung, S., \& Collins, W. A. (2012). Evolution, stress, and sensitive periods: The influence of unpredictability in early versus late childhood on sex and risky behavior. Developmental Psychology, 48, 674-686.

Stearns, S. (1992). The evolution of life histories. Cambridge, England: Oxford University Press.

Stearns, S. C. (1976). Life-history tactics: A review of the ideas. Quarterly Review of Biology, 51, 3-47. doi:10.1086/409052

Sugiyama, L. S., Tooby, J., \& Cosmides, L. (2002). Cross-cultural evidence of cognitive adaptations for social exchange among the Shiwiar of Ecuadorian Amazonia. Proceedings of the National Academy of Sciences, USA, 99, 11537-11542. doi:10.1073/ pnas. 122352999

Taylor, S. E., Klein, L. C., Lewis, B. P., Gruenewald, T. L., Gurung, R. A. R., \& Updegraff, J. A. (2000). Biobehavioral responses to stress in females: Tendand-befriend, not fight-or-flight. Psychological Review, 107, 411-429. doi:10.1037/0033295X.107.3.411

Tooby, J., \& Cosmides, L. (1992). The psychological foundations of culture. In J. H. Barkow, L. Cosmides, \& J. Tooby (Eds.), The adapted mind (pp. 19-136). New York, NY: Oxford University Press.

Tooley, G. A., Karakis, M., Stokes, M., \& Ozanne-Smith, J. (2006). Generalising the Cinderella effect to unintentional childhood fatalities. Evolution and Human Behavior, 27, 224-230. doi:10.1016/j.evolhumbehav 2005.10.001

Tracy, J. L., \& Robins, R. W. (2008). The nonverbal expression of pride: Evidence for cross-cultural recognition. Journal of Personality and Social Psychology, 94, 516-530. doi:10.1037/0022-3514.94.3.516

Turke, P., \& Betzig, L. (1985). Those who can do: Wealth, status, and reproductive success in Ifaluk. Ethology and Sociobiotogy, 6, 79-87. doi:10.1016/0162-3095(85)90001-9

Tversky, A., \& Kahneman, D. (1991). Loss aversion in riskless choice: A reference-dependent model. Quarterly Journal of Economics, 106, 1039-1061. doi:10.2307/2937956

Van Bavel,J.T., \& Cunningham, W. A. (2009). Selfcategorization with a novel mixed-race group moderates automatic social and racial biases. Personality and Social Psychology Bulletin, 35, 321-335.

doi:10.1177/0146167208327743

van de Ven, N., Zeelenberg, M., \& Pieters, R. (2009). Leveling up and down: The experiences of benign and malicious envy. Emotion, 9, 419-429. doi:10.1037/a0015669

Van Vugt, M., De Cremer, D., \& Janssen, D. P. (2007). Gender differences in cooperation and competition:
The male-warrior hypothesis. Psychological Science, 18, 19-23. doi:10.1111/j.1467-9280.2007.01842.x

Vohs, K. D., \& Luce, M. F. (2010). Judgment and decision making. In R. F. Baumeister \& E. J. Finkel (Eds.), Advanced social psychology: The state of the science (pp. 733-756). Oxford, England: Oxford University Press.

Walton, G. M., Cohen, G. L., Cwir, D., \& Spencer, S. J. (2012). Mere belonging: The power of social connections. Journal of Personality and Social Psychology, 102, 513-532. doi:10.1037/a0025731

Webster, G. D. (2003). Prosocial behavior in families: Moderators of resource sharing. Journal of Experimental Social Psychology, 39, 644-652. doi:10.1016/S0022-1031(03)00055-6.

Welling, L. L. M., Conway, C. A., DeBruine, L. M., \& Jones, B. C. (2007). Perceived yulnerability to disease predicts variation in preferences for apparent health in faces. Journal of Evolutionary Psychology, 5 , 131-139. doi:10.1556/JËP.2007.1012

Wiederman, M. W \& \& Allgeier, E. R. (1992). Gender differences in mate selection criteria: Sociobiological or socioeconomic explanation? Ethology and Sociobiology, 13, 115-124. doi:10.1016/01623095(92)90021-U

Wiesenfeld, A. R., Malatesta, C. Z., \& Deloach, L. L. (1981). Differential parental response to familiar and unfamiliar infant distress signals. Infant Behavior and Development, 4, 281-295. doi:10.1016/S01636383(81)80030-6

Wolfe, N. D., Dunavan, C. P., \& Diamond, J. (2007). Origins of major human infectious diseases. Nature, 447, 279-283. doi:10.1038/nature05775

Wrangham, R. W. (1987). The significance of African apes for reconstructing human social evolution. In W. G. Kinzey (Ed.), The evolution of human behavior: Primate models (pp. 51-71). Albany, NY: SUNY Press.

Wrangham, R. W., \& Peterson, D. (1996). Demonic males: Apes and the origins of human violence. Boston, MA: Houghton Mifflin.

Young, S. G., Sacco, D. F., \& Hugenberg, K. (2011). Vulnerability to disease is associated with a domainspecific preference for symmetrical faces relative to symmetrical non-face stimuli. European Journal of Social Psychology, 41, 558-563. doi:10.1002/ejsp.800

Zebrowitz, L. A., Fellous, J. M., Mignault, A., \& Andreoletti, C. (2003). Trait impressions as overgeneralized responses to adaptively significant facial qualities: Evidence from connectionist modeling. Personality and Social Psychology Review, 7, 194-215. doi:10.1207/S15327957PSPR0703 01

Zebrowitz, L. A., Kikuchi, M., \& Fellous, J. M. (2010). Facial resemblance to emotions: Group differences, impression effects, and race stereotypes. Journal 
of Personality and Social Psychology, 98, 175-189. doi:10.1037/a0017990

Zebrowitz, L. A., \& Montepare, J. (2006). The ecological approach to person perception: Evolutionary roots and contemporary offshoots. In M. Schaller, J. A. Simpson, \& D. T. Kenrick (Eds.), Evolution and social psychology (pp. 81-113). New York, NY: Psychology Press.
Zitek, E. M., \& Tiedens, L. Z. (2012). The fluency of social hierarchy: The ease with which hierarchical relationships are seen, remembered, learned, and liked. Journal of Personality and Social Psychology, 102, 98-115. doi:10.1037/a0025345 


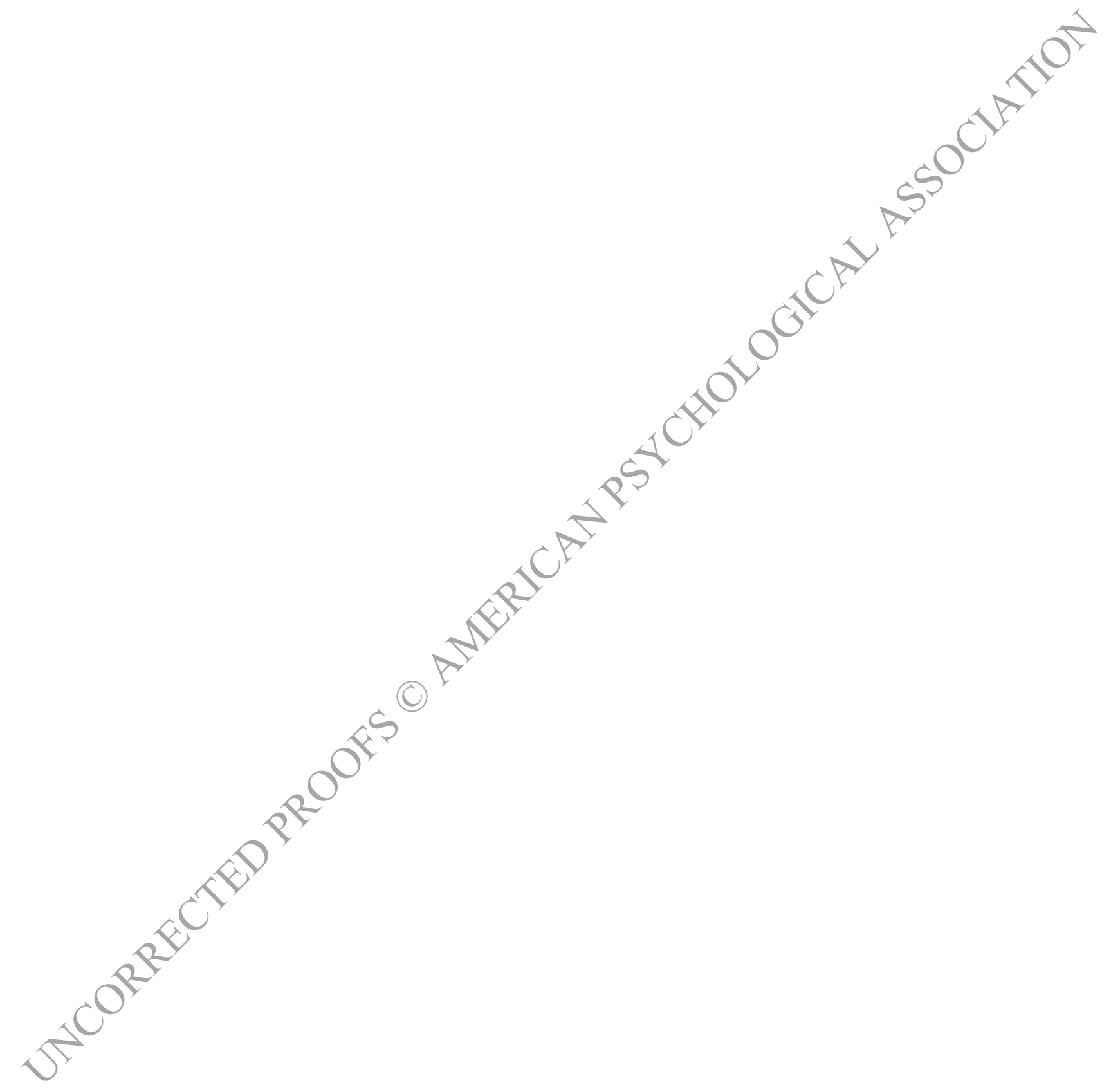

